Subscriber access provided by Caltech Library

\title{
Article
}

\section{Thermodynamic Simulation of the RDX-Aluminum Interface Using ReaxFF Molecular Dynamics}

Ning Wang, Jinhua Peng, Aimin Pang, Tieshan He, Fang Du, and Andres Jaramillo-Botero

J. Phys. Chem. C, Just Accepted Manuscript • DOI: 10.1021/acs.jpcc.7b03108 • Publication Date (Web): 13 Jun 2017

Downloaded from http://pubs.acs.org on June 16, 2017

\section{Just Accepted}

"Just Accepted" manuscripts have been peer-reviewed and accepted for publication. They are posted online prior to technical editing, formatting for publication and author proofing. The American Chemical Society provides "Just Accepted" as a free service to the research community to expedite the dissemination of scientific material as soon as possible after acceptance. "Just Accepted" manuscripts appear in full in PDF format accompanied by an HTML abstract. "Just Accepted" manuscripts have been fully peer reviewed, but should not be considered the official version of record. They are accessible to all readers and citable by the Digital Object Identifier (DOI®). "Just Accepted" is an optional service offered to authors. Therefore, the "Just Accepted" Web site may not include all articles that will be published in the journal. After a manuscript is technically edited and formatted, it will be removed from the "Just Accepted" Web site and published as an ASAP article. Note that technical editing may introduce minor changes to the manuscript text and/or graphics which could affect content, and all legal disclaimers and ethical guidelines that apply to the journal pertain. ACS cannot be held responsible for errors or consequences arising from the use of information contained in these "Just Accepted" manuscripts. 
Thermodynamic Simulation of the RDX-Aluminum Interface Using ReaxFF Molecular Dynamics

Ning Wang ${ }^{1, \S}$, Jinhua Peng ${ }^{1, \S,}$, Aimin Pang ${ }^{2}$, Tieshan $\mathrm{He}^{2}$, Fang $\mathrm{Du}^{2}$, Andres Jaramillo-Botero ${ }^{3, \S}$

1. School of Chemical Engineering, Nanjing University of Science and Technology, Nanjing 210094, China

2. Key laboratory for energetics and safety of solid propellants, Hubei Institute of Aerospace Chemotechnology, Xiangyang 441003, China

3. Chemistry and Chemical Engineering Division, California Institute of Technology, 1200 East California Boulevard, Pasadena, California 91125, United States

Abstract: We use reactive molecular dynamics (RMD) simulations to study the interface between cyclotrimethylene trinitramine (RDX) and Aluminum (Al) with different oxide layers to elucidate the effect of nano-sized Al on thermal decomposition of RDX. A published ReaxFF force field for $\mathrm{C} / \mathrm{H} / \mathrm{N} / \mathrm{O}$ elements was retrained to incorporate $\mathrm{Al}$ interactions, and then used in RMD simulations to characterize compound energetic materials. We find that the predicted adsorption energies for RDX on the $\mathrm{Al}(111)$ surface and the apparent activation energies of RDX and $\mathrm{RDX} / \mathrm{Al}$ are in agreement with ab initio calculations. The $\mathrm{Al}(111)$ surface-assisted decomposition of RDX occurs spontaneously without potential barriers, but the decomposition rate becomes slow when compared with that for RDX powder. We also find that the $\mathrm{Al}(111)$ surface with an oxide layer (Aloxide) slightly increases the potential barriers for decomposition of RDX molecules, while $\alpha-\mathrm{Al}_{2} \mathrm{O}_{3}(0001)$ retards thermal decomposition of RDX, due to the changes in thermal decomposition kinetics. The most likely mechanism for the thermal decomposition of RDX powder is described by the Avrami-Erofeev equation, with $n=3 / 4$, as random nucleation and subsequent growth model. Although the decomposition mechanism of RDX molecules in the RDX/Al matrix complies with three-dimensional diffusion, Jander's equation for RDX(210)/Aloxide and Zhuralev-Lesokin-Tempelman (Z-L-T) equation for $\mathrm{RDX}(210) / \mathrm{Al}_{2} \mathrm{O}_{3}(0001)$ provide a more accurate description. We conclude that the origin of these differences in dynamic behavior is due to the variations in the oxide layer morphologies.

\section{Introduction}

Aluminized explosives are widely used in underwater appliances and thermobaric weapons for their high heats of detonation, strong acceleration ability and long energy 
release time. ${ }^{1-3}$ The detonation properties of cyclotrimethylene trinitramine (RDX) -based aluminized explosives show that micro-sized aluminum $(\mu \mathrm{m}-\mathrm{Al})$ powder that is inert in the detonation wave front, reduces the detonation velocity, pressure, and brisance. $^{4-7}$ Therefore, nano-sized aluminum (nm-Al) particles have attracted much attention over the years, as reactive additives in new formulations of explosives. This is primarily because of their high surface area to volume ratio and the increased rate of chemical reactions when compared to $\mu \mathrm{m}-\mathrm{Al}$ powders. Aluminized explosives containing nm-Al particles provide added power to accelerate metal plates, when compared with $\mu \mathrm{m}-\mathrm{Al}$ powders, ${ }^{8}$ but show no advantage on the other detonation properties, such as heat of detonation, ${ }^{9}$ underwater explosion energies ${ }^{10}$ and driving ability in $50 \mathrm{~mm}$ standard cylinder test. ${ }^{11}$ Gradation of $\mathrm{nm}-\mathrm{Al}$ and $\mu \mathrm{m}-\mathrm{Al}$ particle size and shape can improve the efficiency of Al power release energy. The influence of shape and particle size of $\mathrm{Al}$ on the detonation properties of aluminized explosives stems from specific surface area and active $\mathrm{Al}$ content. ${ }^{12}$ A clear understanding of the interface between RDX and $\mathrm{Al}$ remains elusive, but of ubiquitous importance to predict and assess the role of nm-Al particles on the thermal decomposition of RDX and to improve combustion and detonation process for $\mathrm{RDX} / \mathrm{Al}$ complex in propellants and explosives.

It is believed that detonation initiation by most of the hazardous stimuli including shock, impact, spark, etc., is usually triggered off by "hot spot" formation followed by subsequent thermally-driven events. ${ }^{13}$ The thermodynamics and kinetics of energetic materials and their composite explosives or solid rocket propellants can be characterized by thermogravimetric analysis (TG) and differential scanning calorimetry (DSC). Huang et al ${ }^{14,15}$ studied the effects of aluminum powder with mean diameter $\mathrm{D}_{50}$ of $10.7 \mu \mathrm{m}, 2.6 \mu \mathrm{m}$ and $40 \mathrm{~nm}$, respectively, on the thermal decomposition of RDX with $\mathrm{D}_{50}$ of $80 \mu \mathrm{m}$ by DSC. The results indicate that A1 powders with $\mathrm{D}_{50}$ of $10.7 \mu \mathrm{m}$ and $2.6 \mu \mathrm{m}$ have almost no influence on the thermal decomposition of RDX. In contrast, with $30 \%$ (mass fraction) content of $40 \mathrm{~nm} \mathrm{Al}$, the shoulder peak of RDX covers up the first peak completely and the heat of reaction increases from $600 \mathrm{~kJ} / \mathrm{mo} 1$ to $1600 \mathrm{~kJ} / \mathrm{mol}$. TG-DTG data was used to investigate the most probable reaction mechanism (MPRM) of thermal decomposition of pure RDX as well as mixtures of RDX and 40nm Al particles. The MPRMs deduced from non-isothermal kinetics of RDX in the absence and presence of $\mathrm{Al}$ conform to the Avrami-Erofeev equations with index $n=3 / 4$ and $n=2 / 3$, respectively. However, when 
Liu et $\mathrm{al}^{16}$ investigated thermal stability and sensitivity of RDX-based aluminized explosives with 5-10 $\mu \mathrm{m} \mathrm{Al} \mathrm{particles,} \mathrm{they} \mathrm{concluded} \mathrm{that} \mathrm{the} \mathrm{MPRMs} \mathrm{of} \mathrm{the}$ RDX-based aluminized explosives all conformed to the Z-L-T equation, which describes a three-dimensional diffusion-controlled model. The MPRM for RDX was associated with the Avrami-Erofeev equation, with $n=4$.

In addition to experimental efforts in investigating thermal decomposition properties of RDX-based aluminized explosives, several modeling and simulation studies have been reported in energetic materials, aluminum and RDX/Al compounds. The focus until now, has been on the molecule structure, reaction pathways and intermediates of the gas- and solid-phases of RDX during the thermal decomposition, ${ }^{17-21}$ and the shock-induced initial chemical events of RDX crystal. ${ }^{22-24}$ The oxidation growth kinetics of $\mathrm{Al}$ particles, ${ }^{25,26}$ the morphology and thickness of oxide films on $\mathrm{Al}$ surface have also been studied using computational models. ${ }^{27-29}$ These have shown that amorphous alumina is thermodynamically more stable on $\mathrm{Al}$ surface than any crystalline polymorphs until the thickness of the layer reaches a critical value. ${ }^{30-32}$ The critical thickness depends on the crystallographic orientation of the Al substrate and varies somewhat as a function of temperature and oxygen partial pressure. Hong et $\mathrm{al}^{33}$ used ReaxFF-based RMD simulations to elucidate the oxidation kinetics of $\mathrm{Al}$ nanoparticles and the oxidation states in the oxide layer.

Although there are extensive experimental and theoretical studies on RDX and Al, only a few have reported the interaction between RDX and Al. Umezawa et $\mathrm{al}^{34}$ investigated the decomposition and chemisorptions of an RDX molecule on $\mathrm{Al}(111)$ surface using density functional theory (DFT). Strong attractive forces between oxygen in RDX and the $\mathrm{Al}$ atoms break $\mathrm{N}-\mathrm{O}$ and $\mathrm{N}-\mathrm{N}$ bonds in the RDX, and subsequently, the dissociated oxygen atoms and NO molecules oxidize the Al surface. These reactions occur spontaneously without potential barriers. Similar conclusions were also reached by Ye et al. ${ }^{35}$ Likewise, Guadarrama-Pérez et al ${ }^{36,37}$ used DFT to study the infrared and terahertz spectra of a molecular RDX that was deposited over an Al surface. DFT calculations can accurately describe properties of small finite and periodic systems, but they do not scale well beyond $\sim 100$ atoms; needed to accurately describe interfacial properties in condensed matter systems. In comparison, reactive force field methods such as ReaxFF scale up to millions of atoms and enable RMD simulations over 10's of nanosecond time-scales. The ReaxFF ${ }^{21,46,38}$ reactive force field method describes bond-breaking and bond-formation events based on 
bond-orders applied over the valence atomic interaction terms. ReaxFF allows charges to change as bonds are formed or broken; includes vdW interactions between all atoms, not just non-bonded atoms, thus allowing the valence bonding interaction to be monotonically attractive (vdW inner wall balances the bond attraction); describes valence interactions as a function of the bond order, which goes to zero as the bonds are broken; and can be parameterized directly and systematically from quantum mechanics (QM). It has been successfully applied to many different systems, particularly the thermal- or shock-induced decomposition of energetic materials, melting and crystallization of $\mathrm{Al}$, and oxidation of $\mathrm{Al}$ nanoparticles.

In this work, we performed RMD simulations with ReaxFF force field to study the interfaces between RDX and Al with different oxide layers to elucidate the effect of $\mathrm{nm}-\mathrm{Al}$ on thermal decomposition of $\alpha$-RDX. Starting from the ReaxFF used by Wood et $\mathrm{al}^{39}$ we incorporated and optimized the $\mathrm{Al}$ interaction parameters using the GARFfield parameter optimization framework ${ }^{40}$. We applied the resulting force field to predict the apparent activation energy and the most probable reaction mechanism, validating against experimental results derived from thermal analytical technique. ${ }^{14-16}$ We also analyzed the oxygen diffusion into $\mathrm{Al}$ and the effect of $\mathrm{Al}$ slabs with different morphological surfaces on the evolution of initial species of decomposed RDX molecules. It is of significance to gain an insight into the thermodynamic details at the $\mathrm{RDX} / \mathrm{Al}$ interface. It not only raises our knowledge on the role of $\mathrm{Al}$ in combustion or detonation process of aluminized explosives, but also lays the foundation for later research on the dynamic evolution of nano-sized Al during the detonation wave and theoretical guidelines to prepare micro-nano RDX/Al composites.

\section{Computational details}

\subsection{QM calculations}

The force field was optimized by adding QM training data relevant to the interaction between RDX $(\mathrm{C} / \mathrm{H} / \mathrm{N} / \mathrm{O})^{39}$ and $\mathrm{Al}$. For nonperiodic systems, the QM data was obtained from the density functional theory (DFT) calculations using Gaussian09 with the B3LYP functional and a Pople's 6-311G(d,p) basis set.

The DFT calculations for condensed systems in this study were performed using the CASTEP package ${ }^{41}$ with Vanderbilt-type ultrasoft pseudopotentials and a plane-wave expansion of the wave functions. Exchange and correlation were treated with the generalized gradient approximation, using the functional form of PBE. ${ }^{42}$ The 
electronic wave functions were obtained by a density-mixing scheme ${ }^{43}$ and the structures were relaxed using the BFGS method. ${ }^{44}$ A convergence of $1.0 \times 10^{-6}$ $\mathrm{eV} /$ atom was placed as a criterion on the self-consistent convergence of the total energy. The convergence thresholds for the maximum force and maximum stress during geometry optimization were set to $0.01 \mathrm{eV} / \AA$ and $0.02 \mathrm{GPa}$, respectively. $5 \times 10^{-4} \AA$ was given as the fourth convergence thresholds for the maximum displacement. Brillouin zone sampling was performed using the Monkhost-Pack grid scheme. The values of the kinetic energy cutoff and the k-point grid were determined to ensure the convergence of total energies. In this study, when we calculated equations of state of various crystals, the cutoff energy of plane waves was set to 550 $\mathrm{eV}$. Considering the balance of both computational efficiency and accuracy, ${ }^{35}$ a $4 \times 4$ supercell with four layers was used to study adsorption energies of one molecular RDX on the $\mathrm{Al}(111)$ slab, in which a plane-wave cutoff of $300 \mathrm{eV}$ was used. A $25 \AA$ vacuum slab was put on the $3 \times 3$ slab supercell with two layers of $\alpha-\mathrm{Al}_{2} \mathrm{O}_{3}$, and a plane-wave cutoff of $300 \mathrm{eV}$ was used. K-point separation was below $0.02 \AA^{-1}$ to generate enough k-point grids. A $12 \times 12 \times 12 \mathrm{k}$-point grid was found sufficient for conventional cell of fcc-type Al. A $12 \times 12 \times 12$ k-point grid was selected for primitive cell of $\alpha-\mathrm{Al}_{2} \mathrm{O}_{3}$. A $18 \times 18 \times 12 \mathrm{k}$-point grid was selected for primitive hexagonal cell of AlN. A $18 \times 18 \times 4$ k-point grid was selected for hexagonal representation of $\mathrm{Al}_{4} \mathrm{C}_{3}$.

\subsection{Force field parametrizations}

All simulations were performed using the LAMMPS package ${ }^{45}$ in the framework of potential functions described by the ReaxFF force field. ${ }^{21,46}$ The ReaxFF parametrization for $\mathrm{C} / \mathrm{H} / \mathrm{N} / \mathrm{O} / \mathrm{Al}$ is composed of original $\mathrm{C} / \mathrm{H} / \mathrm{N} / \mathrm{O}$ parameters ${ }^{39}$ and modified Al parameters. ${ }^{33,47-49}$ The $\mathrm{C} / \mathrm{H} / \mathrm{N} / \mathrm{O}$ parameters used here are fully transferable to the "combustion" ReaxFF set described by Chenoweth et al. ${ }^{50}$ The training data captures dissociation pathways and energies for a number of nitramine materials. Several prior publications ${ }^{24,51-54}$ have proved ReaxFF's accuracy to describe thermo-chemistry or mechanical-chemistry coupling in nitramines. The available parameters for Al element have been successfully applied to describe lithium aluminum silicates, ${ }^{47}$ the oxidation of $\mathrm{Al}$ nanoparticles ${ }^{33}$ and metal/epoxy interfaces. ${ }^{49}$ Using the concept of transferability of ReaxFF potentials, we combined and re-optimized the $\mathrm{Al}$ interaction parameters ${ }^{48}$ with those for nitramines. ${ }^{39}$

In order to investigate any possible reaction between RDX and Al, the training set includes cases to describe Al-C, Al-H, Al-N and Al-O bonding interactions, as well as 
3-body combination terms. These are found in combustion products of propellant or oxidation of $\mathrm{Al}$ under certain conditions (e.g. $\mathrm{AlN}, \mathrm{Al}_{2} \mathrm{OC}$ and $\left.\mathrm{Al}_{4} \mathrm{C}_{3}\right)^{55}$. Il'in et al ${ }^{56}$ presented experimental results on combustion in air of ultradisperse Al powder with various additives. An analysis of the chemical and phase compositions of the end combustion products showed the presence of the $\alpha$ and $\gamma-\mathrm{Al}_{2} \mathrm{O}_{3}$ phases, $\mathrm{AlN}, \mathrm{AlON}$ and residual Al. The effect of a carbon additive not only increased the ratio of AlN to AlON from 1.6 to 7 , but also reduced the content of $\mathrm{Al}$ and $\mathrm{Al}_{2} \mathrm{O}_{3}$, which was probably related to the reducing properties of carbon and its compounds. At room temperature, Al-N terms were of great importance and contributed the most to the bonding of epoxy/alumina interfaces. ${ }^{49}$ Streletskii et $\mathrm{al}^{57}$ studied the kinetics of mechanochemical synthesis of $\mathrm{Al}_{4} \mathrm{C}_{3}$ from $\mathrm{Al}$ and graphite powders. The formation of amorphous nuclei of $\mathrm{Al}_{4} \mathrm{C}_{3}$ occurred on the contact surface of nm-Al particles with carbon.

Our training set was divided into two parts. The first one consisted of small molecular clusters, including Al-O-H clusters ${ }^{48}, \mathrm{AlH}_{3}$ clusters ${ }^{58}$ and other clusters containing $\mathrm{NO}_{2}$ with a partially substituted hydrogen atom. Small clusters $\mathrm{Al}\left(\mathrm{CH}_{3}\right)_{3}$ and $\mathrm{Al}\left(\mathrm{NH}_{2}\right)_{3}$ were representative of $\mathrm{Al}-\mathrm{C}$ and $\mathrm{Al}-\mathrm{N}$ bond, respectively. In order to reproduce partial atomic charges, Charge equilibration parameters were obtained from optimized structures of those clusters using Mulliken populations. The second part of the training set included equations of state (EoS) for pure $\mathrm{Al}$ (fcc, hcp, bcc, sc and diamond), $\alpha-\mathrm{Al}_{2} \mathrm{O}_{3}, \mathrm{AlH}_{3},{ }^{59} \mathrm{AlN},{ }^{60} \mathrm{Al}_{4} \mathrm{C}_{3} .{ }^{61}$ The atom and bond parameters were determined from $\mathrm{Al}-\mathrm{X}$ bonds in small clusters and from the EOSs. Angle parameters were trained from the corresponding angle bending energy curves for small clusters with different substituent group. Angles mainly, contain C-Al-X, H-Al-X, N-Al-X, O-Al-X, Al-Al-X, Al-C-X, Al-O-X and Al-N-X, in which $\mathrm{X}$ means one of $\mathrm{C} / \mathrm{H} / \mathrm{N} / \mathrm{O} / \mathrm{Al}$ five elements.

The hybrid genetic-gradient-based reactive force field optimizer (GARFfield) provided by Jaramillo-Botero et $\mathrm{al}^{40}$ was used to systematically prepare the force field. GARFfield is a hybrid multiobjective Pareto-optimal parameter development scheme based on the hybrid combination of genetic algorithms, hill-climbing routines and conjugate-gradient optimization. The principle, optimal strategy and applications can be found in other places. 40,62

\subsection{Simulation setup}

For studying the thermodynamic process at the RDX/Al interface, the simulated 
model system is composed of two regions, one region represented by solid $\alpha$-RDX and the other region by Al with and without a particular oxidized layer (Figure 1). In this work, we chose the (210) plane of RDX crystal in contact with $\mathrm{Al}(111)$ because this crystal plane represents the most sensitive planes perpendicular to shock direction. ${ }^{63-65}$ The oxidized Al(111) slab was obtained by the oxidation of fresh Al(111) slab exposed to a high oxygen gas pressure, which represented the structure of nm-Al to a certain extent. The $\alpha-\mathrm{Al}_{2} \mathrm{O}_{3}(0001)$ slab represented the surface structure of $\mu \mathrm{m}-\mathrm{Al}$, for which most of the authors ${ }^{66-69}$ suggest that the Al powders were coated with a 2-3 nm thick layer of aluminum oxide.

(a)

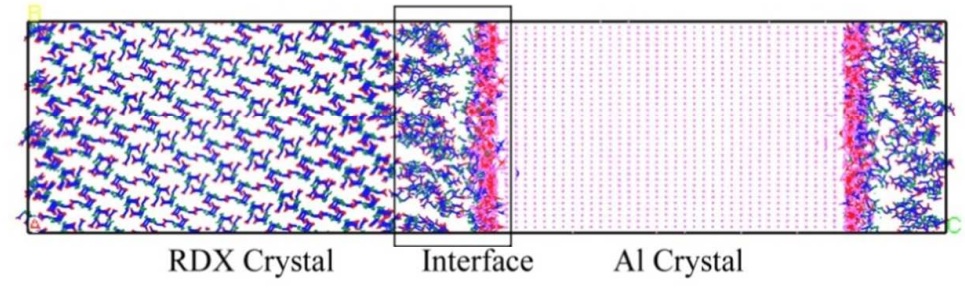

(b)

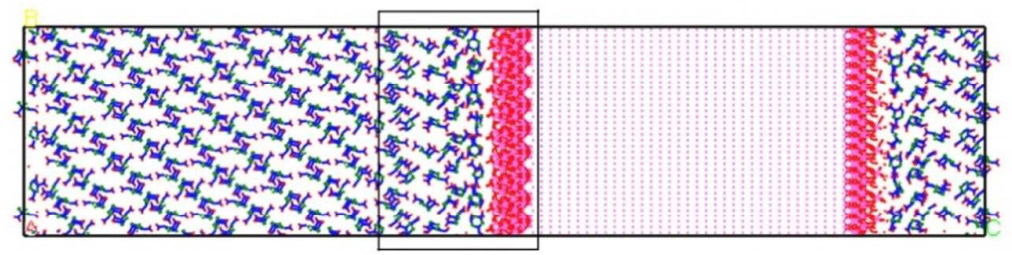

(c)

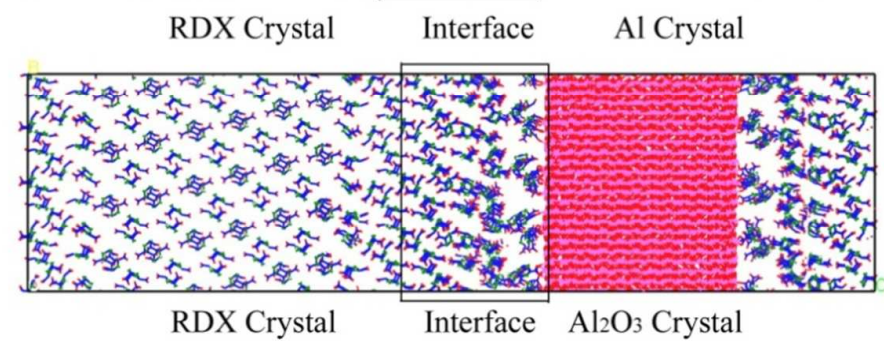

Figure 1. Schematic diagrams of three configurations to study thermodynamic properties of RDX/Al interface, (a) $\mathrm{RDX}(210) / \mathrm{Al}(111)$; (b) $\mathrm{RDX}(210) / \mathrm{Aloxide}$ ( (c) $\mathrm{RDX}(210) / \mathrm{Al}_{2} \mathrm{O}_{3}(0001)$. The initial configurations at $5 \mathrm{~K}$ are further optimized at $100 \mathrm{~K}$ to find a more stable configuration. Color scheme: Red, oxygen; magenta, aluminum; blue, nitrogen; green, carbon; white, hydrogen.

To combine solid $\alpha$-RDX with fcc-type Al in one model, we adjusted the surface vectors and number of repeated units to establish a supercell composed of RDX/Al. The lattice mismatch was confined within 5\% along the two directions perpendicular to the contact direction. The models are described in Table 1. The number of RDX molecules are the same in these three type of RDX/Al complex and the number of $\mathrm{Al}$ is fixed in $\operatorname{RDX}(210) / \mathrm{Al}(111)$ and $\operatorname{RDX}(210) /$ Aloxide models. The density is in the range of $1.75 \sim 1.889,70,71$ for aluminized explosives, so the target density is achieved 
through the adjustment of gap between the two slabs at a constant ratio of $\mathrm{Al} / \mathrm{O}$. The effect of $\mathrm{Al} / \mathrm{O}(\mathrm{wt} \%)$ on thermodynamic properties of $\mathrm{RDX} / \mathrm{Al}$ complex will be studied later.

Table 1. Detailed information of the simulated systems

\begin{tabular}{|c|c|c|c|c|}
\hline Structure & Supercell, $\AA$ & Total atoms & Number Ratio of RDX/Al & Density, $\mathrm{g} / \mathrm{cm}^{3}$ \\
\hline $\mathrm{Bulk} \mathrm{RDX}$ & $22.89 \times 22.56 \times 20.44$ & 1344 & - & 1.89 \\
\hline $\mathrm{RDX}(210) / \mathrm{Al}(111)$ & $40.88 \times 52.52 \times 227.81$ & 31680 & 1.75 & 1.78 \\
\hline $\mathrm{RDX}(210) /$ Aloxide & $40.88 \times 52.52 \times 239.96$ & 34416 & 1.41 & 1.83 \\
\hline $\mathrm{RDX}(210) / \mathrm{Al}_{2} \mathrm{O}_{3}(0001)$ & $40.88 \times 52.52 \times 203.927$ & 33360 & 1.53 & 1.83 \\
\hline
\end{tabular}

\subsection{Non-isothermal Decomposition Kinetics}

The kinetics of heterogeneous decomposition of solids is described by the following equations:

$$
\frac{\mathrm{d} \alpha}{\mathrm{dt}}=\mathrm{k}(\mathrm{T}) \mathrm{f}(\alpha)
$$

Where $\alpha$ is the extent of conversion of RDX molecules, $\mathrm{T}$ is the absolute temperature in $\mathrm{K}$ and $\mathrm{f}(\alpha)$ is the reaction model called the conversion function. In Eq.(1), $\mathrm{k}(\mathrm{T})$ is the Arrhenius rate constant, which is given as

$$
\mathrm{k}(\mathrm{T})=\operatorname{Aexp}\left(-\frac{\mathrm{E}}{\mathrm{RT}}\right)
$$

where $\mathrm{A}$ is the pre-exponential factor, $\mathrm{E}$ is the activation energy, and $\mathrm{R}$ is the gas constant.

For nonisothermal decomposition simulations, the system was initially equilibrated at $5 \mathrm{~K}$ using RMD with an isothermal-isochoric (NVT) ensemble during 10 ps to optimize the structure of RDX/Al complex. Then, the system was linearly heated at a rate in the range from $1 \mathrm{~K} / \mathrm{ps}$ to $200 \mathrm{~K} / \mathrm{ps}$, up to a final temperature of $4000 \mathrm{~K}$. RMD simulations in the NVT ensemble were performed using a velocity Verlet algorithm and a time step of 0.1 fs to conserve energy and capture chemical species. The system's temperature was controlled using a Nose/Hoover thermostat with a temperature damping constant of $10 \mathrm{fs}$ implemented on the 10 Feb 2015 version of LAMMPS code. Simulations had been carried out on four 20-processor nodes of an Intel Xeon/Pentium 4 based LINUX cluster.

We calculated thermodynamic parameters using 2 kinetic analysis methods, which are listed in Table 2. The Ozawa method is independent of a mechanism function, so its apparent activation energy is usually regarded as the real activation energy. The Šatava-Šesták equation is introduced to determine the most probable kinetic model 
function $G(\alpha)$, which is selected from 31 types of kinetic model functions ${ }^{72}$ (shown in Table S1 of supporting information). Each kinetic model function and the $\alpha$-T data of RDX molecules at various heating rates are put into the integral equation to calculate the values of $E_{s}, A_{s}$ and correlation coefficient $R$. $R$ is chosen as statistical criteria to determine $G(\alpha)$. The values of $A$ and $E$ obtained by the Ozawa method, and are also applied to validate $\mathrm{G}(\alpha)$.

Table 2. Kinetic analysis methods

\begin{tabular}{|c|c|}
\hline Method & Equation \\
\hline Flynn-Wall-Ozawa & $\lg \beta=\lg \left(\frac{\mathrm{AE}}{\mathrm{RG}(\alpha)}\right)-2.315-0.4567 \frac{\mathrm{E}_{\text {ozawa }}}{\mathrm{RT}}$ \\
\hline Šatava-Šesták & $\lg (\alpha)=\lg \frac{\mathrm{A}_{\mathrm{s}} \mathrm{E}_{\mathrm{s}}}{\mathrm{R} \beta}-2.315-0.4567 \frac{\mathrm{E}_{\mathrm{s}}}{\mathrm{RT}}$ \\
\hline
\end{tabular}

a , conversion degree; $\mathrm{T}$, temperature at time $\mathrm{t}$; $\mathrm{R}$, gas constant; A, pre-expotential factor; $\mathrm{E}$, apparent activation energy; $G(\alpha)$, integral mechanism function; $T_{p}$, peak temperature of DSC curve.

\section{Results and discussions}

\subsection{Validation of the modified force field}

In order to accurately describe aluminum in the condensed phase and its oxidation products using ReaxFF RMD simulations, the QM training set used includes descriptions for different crystalline phases. Figure 2 4 shows equations of state (EOS) curves that are generated by performing complete relaxations on aluminum unit cells at various fixed volumes (cold compression curves). The QM and ReaxFF results in a single graph for each crystalline phases are also shown in Figure S1 S8 of supporting information. Our results indicate that ReaxFF calculations agree well with existing DFT values. These data points were then used to generate a plot of the total energy as a function of the lattice volume, which were fitted to the Birch-Murnaghan formula $^{73}$ yielding equilibrium lattice constants and bulk modulus, shown in Table 3. Cohesive energy was calculated by the difference between the average energy of the free atoms and that of a crystal. It is concluded from Table 3 that the Birch-Murnaghan formula identifies the correct equilibrium volume and bulk modulus for various crystals with ReaxFF and DFT values. Calculations using the modified ReaxFF provide a good description of cell axes lengths, bulk modulus and cohesive energies, compared to DFT values and available experimental results.

Other calculated dissociation energy profiles for various bonds and angles are 
shown in Figure S9 S32 of supporting information. Our ReaxFF calculations using the fitted parameters agree well for charge distribution, equilibrium structures of clusters, bond and angle dissociation energies for most systems tested. It also shows the same trend in EOS of $\mathrm{Al}_{2} \mathrm{O}_{3}$ (Corundum type $\left(\alpha-\mathrm{Al}_{2} \mathrm{O}_{3}\right), \mathrm{Rh}_{2} \mathrm{O}_{3}$ type and $\mathrm{CaIrO}_{3}$ type) and $\mathrm{AlO}_{2}$ crystal structures calculated by CASTEP and ReaxFF using the fitted parameters. However, it's noted that only EOS of $\alpha-\mathrm{Al}_{2} \mathrm{O}_{3}{ }^{48}$ was included in the training set, so it's suggested that more information of alumina be added into the training set to investigate the high-pressure behavior ${ }^{74-76}$ and it would be more appropriate to retrain parameters of both aluminum and oxygen elements, although the modified force field in this work accurately describes low pressure range ( $40 \mathrm{GPa}$ ) for aluminized explosives.
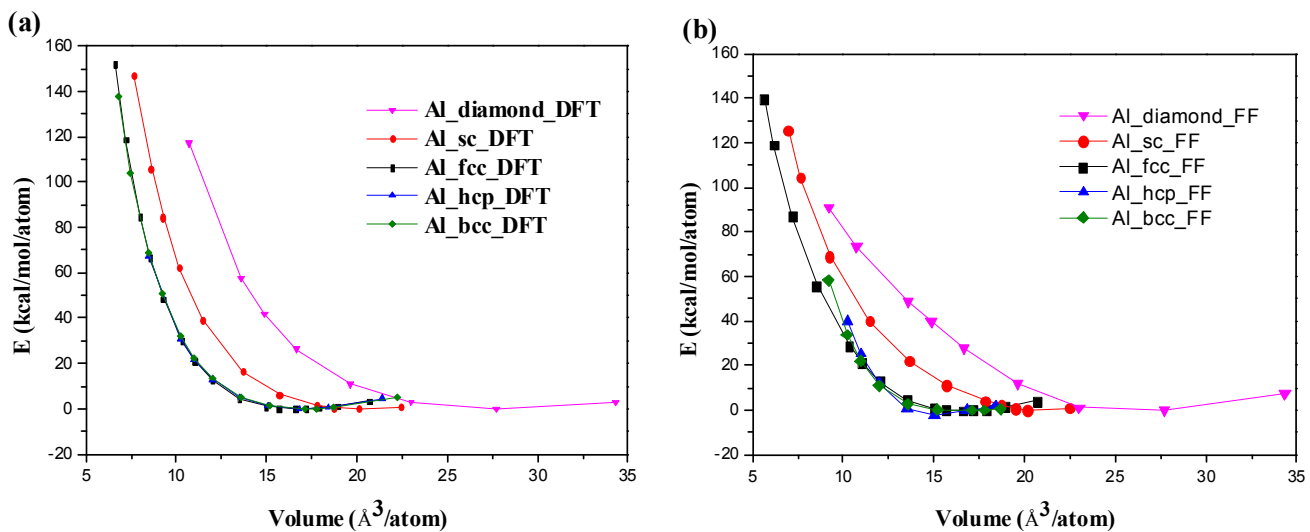

Figure 2. Equation of state for five crystal structures (fcc, sc, diamond, hcp, bcc) calculated using (a) CASTEP method and (b) ReaxFF using the fitted parameters.
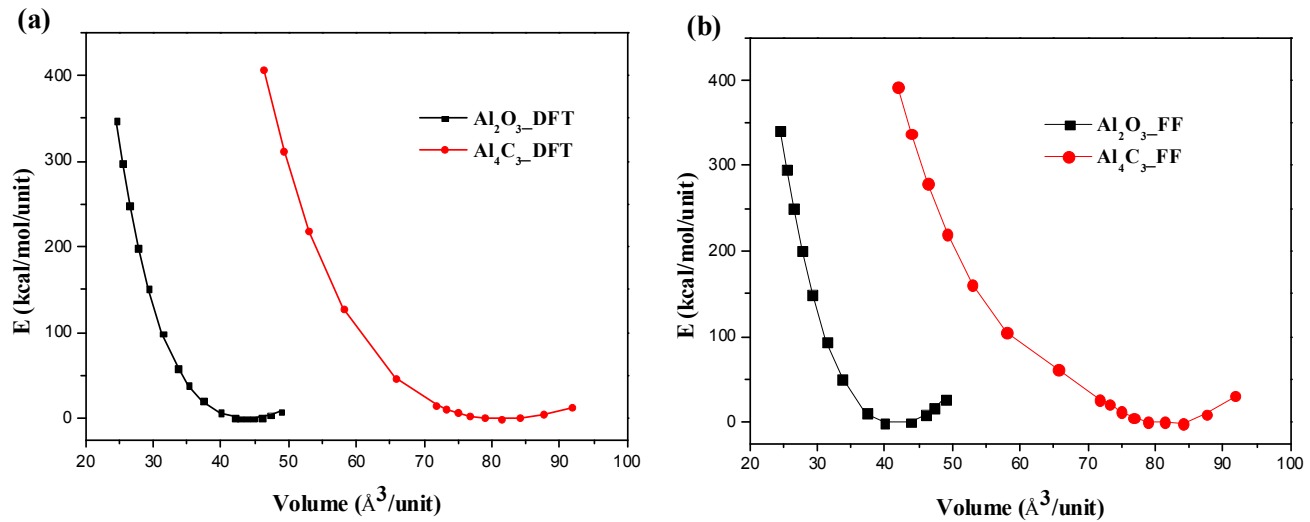

Figure 3. Equation of state for $\mathrm{Al}_{4} \mathrm{C}_{3}$ and $\alpha-\mathrm{Al}_{2} \mathrm{O}_{3}$ using (a) CASTEP method and (b) ReaxFF using the fitted parameters. 

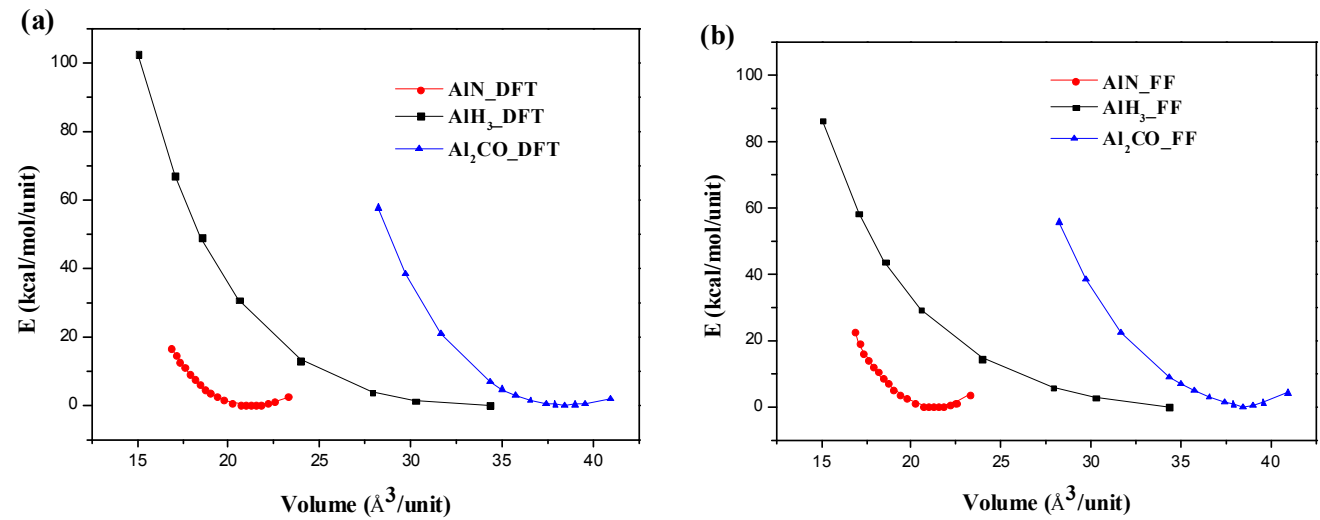

Figure 4. Equation of state for $\alpha-\mathrm{AlH}_{3}, \mathrm{AlN}$ and $\mathrm{Al}_{2} \mathrm{CO}$ using (a) CASTEP method and (b) ReaxFF using the fitted parameters.

Table 3. DFT, ReaxFF and Forcite results (at $0 \mathrm{~K}$ ) compared to experimental data from the literature (at room temperature) for the cell axes, cohesive energies $E_{c}$, bulk modulus $B$ of various crystals

\begin{tabular}{|c|c|c|c|c|c|}
\hline Structure & Property & CASTEP & ReaxFF & Forcite & Experiments \\
\hline Al_fcc & $\mathrm{a} / \AA$ & 4.07 & 4.05 & 4.04 & 4.049 \\
\hline \multirow[t]{2}{*}{ FM-3M } & $\mathrm{E}_{\mathrm{c}} / \mathrm{eV}$ & 3.746 & 3.316 & 1.39 & $3.36^{48}$ \\
\hline & $\mathrm{B} / \mathrm{GPa}$ & 84 & 80 & 81.5 & $79^{48}$ \\
\hline $\mathrm{Al}_{2} \mathrm{O}_{3}$ & $\mathrm{a} / \AA$ & 4.805 & 4.812 & 4.76 & 4.759 \\
\hline \multirow[t]{3}{*}{$\mathrm{R}-3 \mathrm{C}$} & $\mathrm{c} / \AA$ & 13.125 & 13.149 & 12.96 & 12.991 \\
\hline & $\mathrm{E}_{\mathrm{c}} / \mathrm{eV}$ & 37.533 & 34.423 & 164.98 & $32^{48}$ \\
\hline & $\mathrm{B} / \mathrm{GPa}$ & 228 & 235 & 289.7 & $253^{48}$ \\
\hline $\mathrm{AlH}_{3}$ & $\mathrm{a} / \AA ̊$ & 4.467 & 4.457 & \multirow{3}{*}{$\begin{array}{c}\text { No force field } \\
\text { parameters }\end{array}$} & 4.449 \\
\hline \multirow[t]{2}{*}{$\mathrm{R}-3 \mathrm{C}$} & $\mathrm{c} / \AA$ & 11.847 & 11.848 & & 11.804 \\
\hline & $\mathrm{B} / \mathrm{GPa}$ & 36 & 38.8 & & \\
\hline AlN & $\mathrm{a} / \AA$ & 3.135 & 3.152 & \multirow{3}{*}{$\begin{array}{c}\text { No force field } \\
\text { parameters }\end{array}$} & 3.11 \\
\hline \multirow[t]{2}{*}{ P63MC } & $\mathrm{c} / \AA$ & 5.038 & 5.089 & & 4.98 \\
\hline & $\mathrm{B} / \mathrm{GPa}$ & 222 & 221 & & $208^{60}$ \\
\hline $\mathrm{Al}_{4} \mathrm{C}_{3}$ & $\mathrm{a} / \AA ̊$ & 3.349 & 3.332 & \multirow{3}{*}{$\begin{array}{c}\text { No force field } \\
\text { parameters }\end{array}$} & 3.331 \\
\hline \multirow[t]{2}{*}{$\mathrm{R}-3 \mathrm{M}$} & $\mathrm{c} / \AA$ & 25.107 & 24.670 & & 24.99 \\
\hline & $\mathrm{B} / \mathrm{GPa}$ & 159.5 & 141.7 & & \\
\hline
\end{tabular}

Before investigating the interface between RDX and $\mathrm{Al}$, the behavior of $\mathrm{Al}$, as a surface-active material, was identified. The surface properties were not explicitly entered into the training set, so it serves to test the accuracy of the prepared ReaxFF force field against DFT calculations. Of particular interest is the surface formation energy $\left(\mathrm{E}_{\mathrm{sf}}\right)$, defined by

$$
\mathrm{E}_{\mathrm{sf}}=\left(\mathrm{E}_{\mathrm{slab}}-\mathrm{nE} \mathrm{E}_{\mathrm{bulk}}\right) /(2 \mathrm{~A})
$$

where $E_{\text {slab }}$ is the energy of the relaxed crystal slab exposed to a vacuum, $\mathrm{n}$ is the 
number of atoms in the slab, $E_{\text {bulk }}$ is the cohesive energy per atom of the bulk phase, and $\mathrm{A}$ is the area of the surface exposed to vacuum. A minimum of $20 \AA$ was used for the vacuum layer. For the cubic phases (fcc, bcc) of Al, this was done for low-Miller index surfaces; (100), (110), and (111). For the hcp phase, we investigated the (0001) surface. We also calculated the $\mathrm{E}_{\mathrm{sf}}$ of $\mathrm{Al}_{2} \mathrm{O}_{3}(0001)$. The surface formation energies listed in Table 4 confirm that ReaxFF is able to reproduce the correct rumpling trends, which is critical in describing surface chemistry. Nonetheless, ReaxFF tends to underestimate the surface formation energies when compared to DFT results. This underestimation is also found in other articles. ${ }^{48,77}$ It suggests room for improvement in the force field parameters of $\mathrm{Al}$, possibly by including low-gradient dispersion corrections as well as vacancy-mediated diffusion barriers for various crystals and adsorption energies of different small clusters on surface formation energies of the expected crystalline phases for Al.

Table 4. Surface formation energies using ReaxFF as compared with CASTEP and Forcite calculations, in unit of $\mathrm{J} / \mathrm{m}^{2}$

\begin{tabular}{|c|c|c|c|}
\hline Surface & Castep* $^{*}$ & ReaxFF* & \% Difference \\
\hline fccAl (111) & $0.832\left(0.81^{48}\right)$ & $0.506\left(0.576^{48}\right)$ & -39.18 \\
\hline fccAl (110) & 1.070 & 0.669 & -37.48 \\
\hline fccAl (100) & 1.039 & 0.577 & -44.47 \\
\hline fccAl (111) & 0.875 & 0.698 & -20.23 \\
\hline fccAl (110) & 0.762 & 0.461 & -39.50 \\
\hline fccAl (100) & 1.002 & 0.894 & -10.78 \\
\hline hcpAl (0001) & 0.732 & 0.463 & -36.75 \\
\hline $\mathrm{Al}_{2} \mathrm{O}_{3}(0001)$ & $1.793\left(1.59^{48}\right)$ & $2.138\left(1.0^{48}\right)$ & 19.24 \\
\hline $\mathrm{RDX}(210)$ & 0.42 & 0.276 & -34.28 \\
\hline
\end{tabular}

*QM and ReaxFF results are from this work except four data in round brackets.

Impingement of $\mathrm{RDX}$ on the $\mathrm{Al}$ surface is used to study the $\mathrm{RDX}-\mathrm{Al}$ interfacial interactions. We calculated the chemical adsorption energies of one RDX molecule on Al(111) surface. The corresponding adsorption energy ${ }^{35}\left(E_{a d s}\right)$ was calculated by

$$
\mathrm{E}_{\mathrm{ads}}=\mathrm{E}_{\text {adsorbed slab }}-\mathrm{E}_{\text {molecule+slab }}
$$

where $E_{\text {adsorbed slab }}$ is the total energy of the optimized structure formed after the RDX molecule is chemically absorbed on the Al slab and $E_{\text {molecule+slab is the }}$ non-interacting total energy for an RDX molecule and the slab system (RDX molecule is as far as $10.0 \AA$ away from Al surface). The adatoms were placed on different top, hcp or fcc sites and were also put initially parallel to the Al surface. ${ }^{34}$ The DFT calculations were fully relaxed such that the adatom was allowed to move to 
a local energy minimum. Chemical adsorption energies are presented in Table 5. The initial and adsorption configurations are shown in Figure S33 and S34 of supporting information. ReaxFF performs well at predicting adatom adsorption energies when compared to DFT calculations. Combined with chemical adsorption energies, surface formation energies, cohesive energies and bulk modulus, these results show that the modified reactive force field provides a good overall fit to the quantum mechanical data.

Table 5. Chemical adsorption energies using ReaxFF as compared with CASTEP calculations, in unit of $\mathrm{kcal} / \mathrm{mol}$

\begin{tabular}{|c|c|c|c|c|c|}
\hline Structure & Adsorption sites & CASTEP & ReaxFF & $\%$ Difference & Remaks \\
\hline Rdxalv1 & Top & -185.4 & -195.5 & 5.45 & \multirow{3}{*}{$\begin{array}{l}\text { Vertical adsorption of N-N } \\
\text { bond of RDX molecule in } \\
\text { axial position to Al slab }\end{array}$} \\
\hline Rdxalv2 & Hcp & -90.8 & -85.8 & -5.51 & \\
\hline Rdxalv3 & Fcc & -83.9 & -87.8 & 4.65 & \\
\hline Rdxalp1 & --- & -274.0 & -305.5 & 11.50 & \multirow{2}{*}{$\begin{array}{l}\text { parallel adsorption of RDX } \\
\text { molecule to Al slab }\end{array}$} \\
\hline Rdxalp2 & --- & -138.3 & -151.7 & 9.69 & \\
\hline
\end{tabular}

Different surface structures for the aluminum crystal slab were obtained by oxidation using RMD simulations with the prepared ReaxFF force field. An initial configuration of the $\mathrm{Al}$ (431) slab with 150 random oxygen molecules (oxygen density of $0.49 \mathrm{~g} / \mathrm{cm}^{3}$ ) was constructed. ${ }^{33}$ A second surface structure composed of an Al (111) slab $(3.95 \times 5.14 \times 19.0 \mathrm{~nm})$ at the same oxygen density was also prepared. Then, a third and final structure was obtained by heating the simulation box from $5 \mathrm{~K}$ to the target temperatures $(473 \mathrm{~K}, 573 \mathrm{~K}$ and $673 \mathrm{~K})$ and back to $5 \mathrm{~K}$ at a heating/cooling rate of $3.12 \mathrm{~K} / \mathrm{ps}$ for three cycles, as shown in Figure 5(a). Figure 5(b) shows the oxide layer thickness of $\mathrm{Al}(431)$ slab at $473 \mathrm{~K}, 573 \mathrm{~K}$ and $673 \mathrm{~K}$ and $\mathrm{Al}(111)$ slab at $573 \mathrm{~K}$ as a function of time. We find that the thickness of oxide film in $\mathrm{Al}(431)$ slab is similar to that reported from computational ${ }^{33}$ and experimental results. ${ }^{30}$ Furthermore, the oxide layer in $\mathrm{Al}(431)$ slab is thicker than that in $\mathrm{Al}(111)$ slab, because atoms are packed more densely in the Al(111) slab surface, which tends to reduce oxidation. 

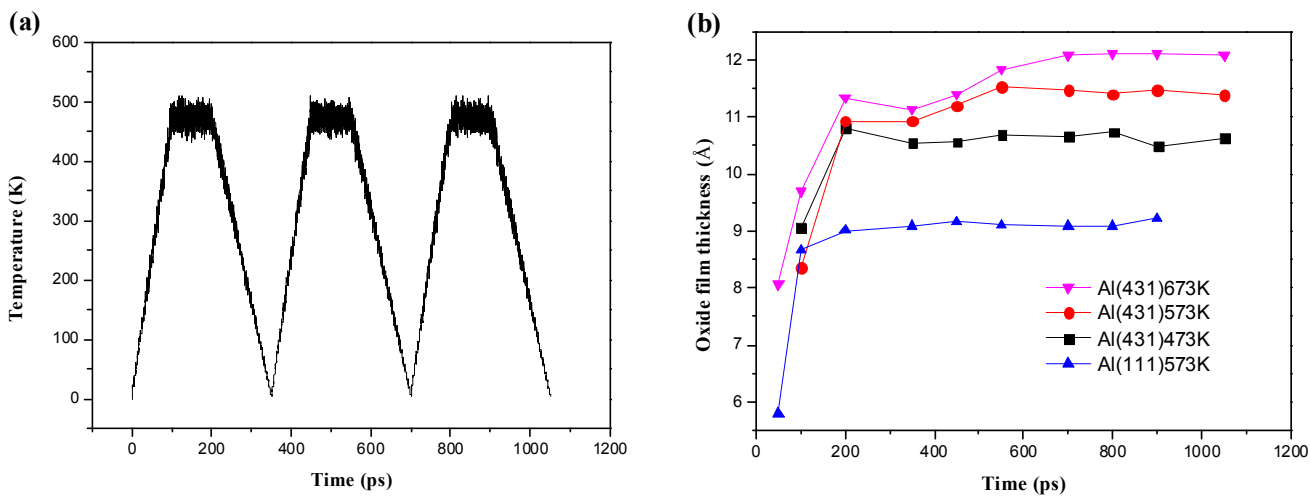

Figure 5. The oxidation of Al slab using ReaxFF. The relationship between dynamic temperature and time for the target temperature of $473 \mathrm{~K}$ (a). The thickness of oxide film in $\mathrm{Al}$ slab as a function of time (b).

\subsection{Thermodynamic properties of RDX and RDX/Al complex}

The optimized ReaxFF parameters were used to calculate thermodynamic properties of RDX and $\mathrm{RDX}(210) / \mathrm{Al}(111)$ complex at heating rates of $140 \mathrm{~K} / \mathrm{ps}$ and $40 \mathrm{~K} / \mathrm{ps}$, respectively. Figure 6(a) shows the number of decomposed RDX molecules and potential energies as a function of time. The initial rise in the potential energy is seen as a potential barrier due to the uniform heating, with a further discussion shown in Figure S35 of supporting information. Before RDX molecules decompose, it needs to absorb enough energy from ambient heating bath to enhance frequencies of bond modes and conformational changes ${ }^{36}$ from AAE (RDX molecule with two nitro groups in axial positions and one in the equatorial position) to AAA (RDX molecule with the three nitro groups in axial positions). A snapshot of RDX crystal at 44 ps at a heating rate of $40 \mathrm{~K} / \mathrm{ps}$ is available in Figure S36 of supporting information. Then, the potential energy decreases with time as the exothermic reactions progress.

Figure 6(b) shows decrease for both potential energies and the number of RDX molecules in $\operatorname{RDX}(210) / \mathrm{Al}(111)$ complex. The $\mathrm{Al}(111)$ plane can induce decomposition of RDX molecules without a reaction barrier, which is due to the strong attractive interaction between $\mathrm{O}$ and $\mathrm{Al}$ atoms. However, decomposition time is over $60 \mathrm{ps}$ at a heating rate of $140 \mathrm{~K} / \mathrm{ps}$ for $\mathrm{RDX}(210) / \mathrm{Al}(111)$ complex, much longer than 30 ps for RDX crystal. The kinetic mechanism changes in thermal decomposition of RDX molecules would be discussed later. 

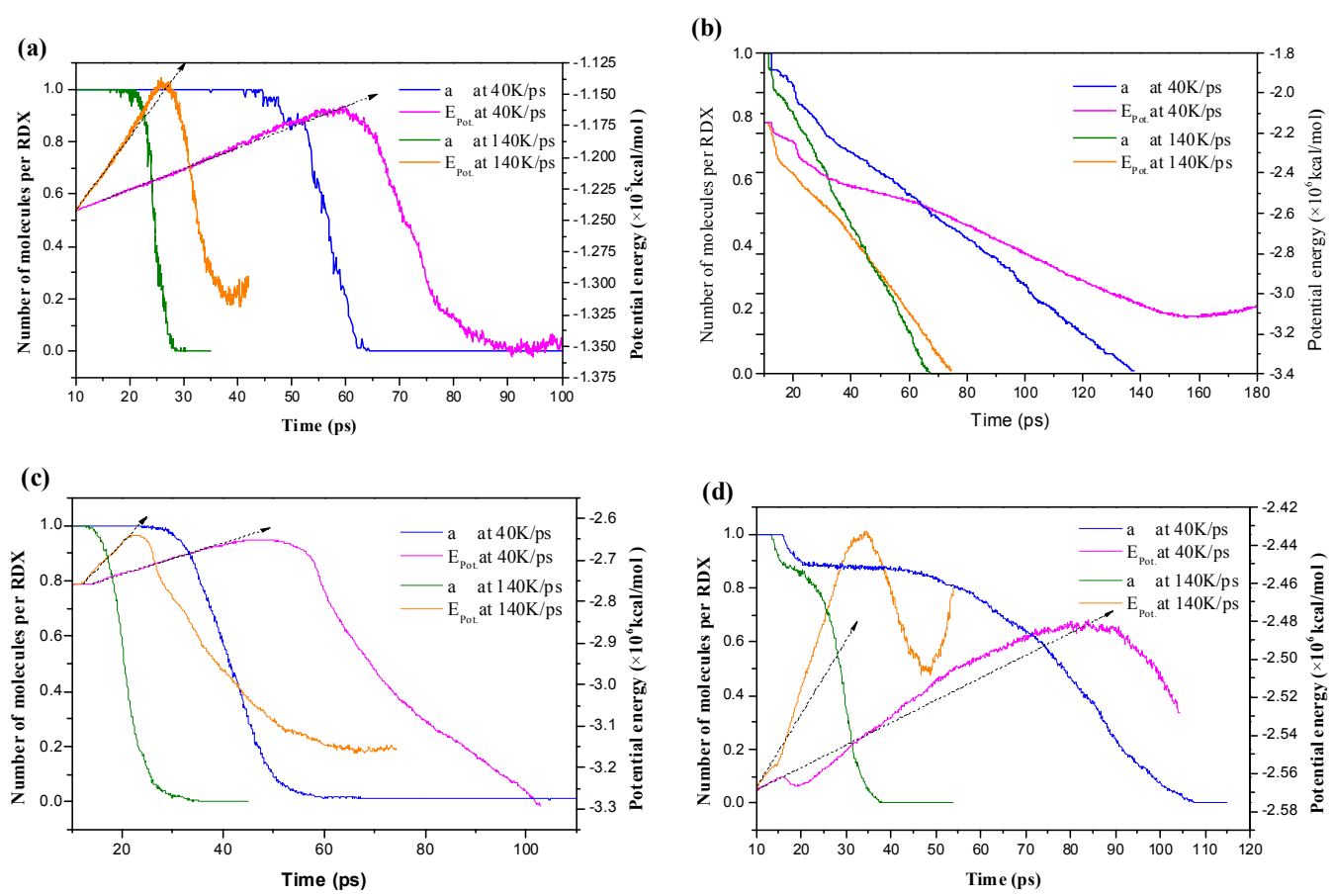

Figure 6. The potential energies and the number of decomposed RDX molecules at a heating rate of $140 \mathrm{~K} / \mathrm{ps}$ and $40 \mathrm{~K} / \mathrm{ps}$ for $\mathrm{RDX}(\mathrm{a}), \operatorname{RDX}(210) / \mathrm{Al}(111)$ (b), $\mathrm{RDX}(210) /$ Aloxide (c), $\mathrm{RDX}(210) / \mathrm{Al}_{2} \mathrm{O}_{3}(0001)$ (d), respectively. Green lines and blue lines are the number ratio of remaining RDX to total RDX molecules at $140 \mathrm{~K} / \mathrm{ps}$ and $40 \mathrm{~K} / \mathrm{ps}$. Orange lines and magenta lines are the potential energies at $140 \mathrm{~K} / \mathrm{ps}$ and $40 \mathrm{~K} / \mathrm{ps}$.

Although the interaction between RDX and Al may occur spontaneously without potential barriers, adhesive ingredients are widely used in plastic-bonded explosives and HTPB-based solid propellants in addition to RDX and Al. This may be due to the compact oxidized layer on the $\mathrm{Al}$ surface that hinders the interaction between RDX molecules and fresh $\mathrm{Al}$ atoms. Therefore, it is essential to investigate the thermodynamic properties of mixtures of RDX and oxidized Al. We first obtained an oxidized Al slab by exposing a bare $\mathrm{Al}(111)$ slab to a high density oxygen gas, as described in section 3.1. Then, a model composed of the oxidized Al slab and an RDX(210) slab (RDX/Aloxide) was used to study thermodynamic properties. Figure 6(c) presents the time profiles of potential energy and the number of decomposed RDX molecules for this system at heating rates of $140 \mathrm{~K} / \mathrm{ps}$ and $40 \mathrm{~K} / \mathrm{ps}$. Potential barriers still exist in the RDX/Aloxide complex, but the decomposition rate of RDX molecules rises. The time relating to the rapidest decomposition rate of RDX molecules is $21.1 \mathrm{ps}$ at a heating rate of $140 \mathrm{~K} / \mathrm{ps}$ and $41.4 \mathrm{ps}$ at $40 \mathrm{~K} / \mathrm{ps}$ for the RDX/Aloxide, respectively, while it is $24.7 \mathrm{ps}$ at $140 \mathrm{~K} / \mathrm{ps}$ and $60.9 \mathrm{ps}$ at $40 \mathrm{~K} / \mathrm{ps}$ for RDX crystal. At longer times, the potential energy decreases due to secondary 
decomposition of RDX fragments and oxidization of Aloxide slab.

As the thickness of the oxidized layer in $\mu \mathrm{m}-\mathrm{Al}$ particle is known to be a few nanometers regardless of the particle size, we used the $\alpha-\mathrm{Al}_{2} \mathrm{O}_{3}$ plane to stand for $\mu \mathrm{m}-\mathrm{Al}$ particles. Note that the $\alpha-\mathrm{Al}_{2} \mathrm{O}_{3}(0001)$ surface can be terminated with a single Al layer, a double Al layer, or an O layer. We chose one Al-terminated layer as $\alpha-\mathrm{Al}_{2} \mathrm{O}_{3}(0001)$ surface ${ }^{48}$. The thermodynamic process of $\mathrm{RDX}(210) / \mathrm{Al}_{2} \mathrm{O}_{3}(0001)$ complex is depicted in Figure 6(d). At first stage, about 12\% percent of the number of RDX molecules are absorbed on the bare $\mathrm{Al}_{2} \mathrm{O}_{3}(0001)$ plane. Then, the surplus number of RDX molecules gradually decreases. Subjected to the negative effect of $\mathrm{Al}_{2} \mathrm{O}_{3}$, the potential energy of $\mathrm{RDX} / \mathrm{Al}_{2} \mathrm{O}_{3}(0001)$ complex deviates largely from the linear line. The time at the fastest decomposition rate of RDX molecules is by $29.3 \mathrm{ps}$ at a heating rate of $140 \mathrm{~K} / \mathrm{ps}$ and by $81.3 \mathrm{ps}$ at $40 \mathrm{~K} / \mathrm{ps}$ for $\mathrm{RDX}(210) / \mathrm{Al}_{2} \mathrm{O}_{3}(0001)$ complex, respectively. From the decomposition time and high potential barrier, we conclude that it takes longer time for the RDX molecules to decompose at $\mathrm{RDX} / \mathrm{Al}_{2} \mathrm{O}_{3}(0001)$ interface, than those at the pure RDX crystal interface.

\subsection{Non-isothermal decomposition kinetics of RDX/Al complex}

In order to investigate the kinetic properties of $\mathrm{RDX} / \mathrm{Al}$ complex, we carried out RMD simulations in the canonical ensemble (NVT) using a linear heating rate $\beta$ in the range of $200 \mathrm{~K} / \mathrm{ps}$ to $1 \mathrm{~K} / \mathrm{ps}$. The number of RDX molecules was set to be proportional to the concentration of reactants. The number of intact RDX molecules and fragment information were postprocessed by the mol_fra.c code, which was contributed by Zybin et al. The consumption of RDX molecules was defined to be a sigmoidal ("S" shaped) type curve as a function of time. The temperature $\mathrm{T}$, at which the maximum reaction rate occurred, was related to the fastest decrease in RDX molecules. An example is presented in Figure S37 of supporting information and the relationship between $\log \beta$ and $1 / \mathrm{T}$ is shown in Figure 7. Combined with Ozawa method shown in Table 2, the obtained activation energy is listed in Table 6. The oxidized Al brings down the apparent activation energy of RDX crystal from 137 $\mathrm{kJ} / \mathrm{mol}$ to $96 \mathrm{~kJ} / \mathrm{mol}$, while fresh $\mathrm{Al}_{2} \mathrm{O}_{3}(0001)$ slab hinders thermal decomposition of RDX molecules.

The experimentally reported activation energy of RDX crystal varies from 103 $\mathrm{kJ} / \mathrm{mol}$ to $272 \mathrm{~kJ} / \mathrm{mol}^{14,78-81}$ and the reported activation energy of RDX/Al mixtures changes from $94 \mathrm{~kJ} / \mathrm{mol}$ to $349 \mathrm{~kJ} / \mathrm{mol}^{14,16,80,82-84}$ A compensation effect exists between the apparent activation energy $\mathrm{E}(\mathrm{kJ} / \mathrm{mol})$ and pre-exponential factor $(\log \mathrm{A}$, 
$\mathrm{s}^{-1}$ ) for both RDX and the RDX/A1 samples, which can be described by $\log (\mathrm{A})=$ $0.1027 \mathrm{E}-1.8409$. Therefore, although ReaxFF calculations are in good agreement with the experimental results, it should be noted that the apparent activation energy may be slightly changed by these factors such as the degree of oxidation of Al slab, the ratio of RDX to $\mathrm{Al}$ and the density of mixtures. Further work would be needed to demonstrate this.

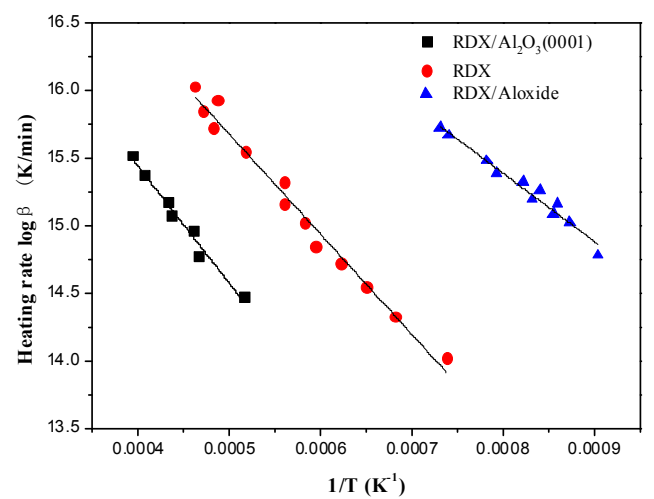

Figure 7. Different heating rate $\log \beta$ as a function of $1 / \mathrm{T}$. The corresponding temperature $\mathrm{T}$, at which the maximum reaction rate occurs, is related to the fastest decrease in the number of RDX molecules.

Table 6. Kinetic parameter of RDX and RDX/Al obtained from ReaxFF and experiments

\begin{tabular}{|c|c|}
\hline Structure* & Eozawa,kJ/mol \\
\hline RDX bulk & 137.3 \\
\hline $\mathrm{RDX}(210) /$ oxidized $\mathrm{Al}(111)$ & 91.6 \\
\hline $\mathrm{RDX}(210) / \mathrm{Al}_{2} \mathrm{O}_{3}(0001)$ & 156.7 \\
\hline $\mathrm{RDX}(80 \mu \mathrm{m})^{14}$ & 135.0 \\
\hline $\mathrm{RDX}(80 \mu \mathrm{m}) / \mathrm{Al}(40 \mathrm{~nm})^{14}$ & 98.0 \\
\hline $\mathrm{RDX}(80 \mu \mathrm{m}) / \mathrm{Al}(2.6 \mu \mathrm{m})^{14}$ & 129.0 \\
\hline $\mathrm{RDX}(80 \mu \mathrm{m}) / \mathrm{Al}(10.7 \mu \mathrm{m})^{14}$ & 157.0 \\
\hline $\mathrm{RDX}(23 \mu \mathrm{m}) / \mathrm{Al}(140 \mathrm{~nm})^{82}$ & 115.9 \\
\hline $\mathrm{RDX} / \mathrm{Al}(5-10 \mu \mathrm{m})^{16}$ & 150.5 \\
\hline
\end{tabular}

*the mean diameter $\mathrm{D}_{50}$ of particles is listed in bracket.

Using the method introduced in Section 2.4, we analyzed the kinetics of RDX and $\mathrm{RDX} / \mathrm{Al}$ complex at different heating rates. The heating rate doesn't affect the most probable kinetic model function $\mathrm{G}(\alpha)$ as $\operatorname{long}$ as $\log \beta$ and $1 / \mathrm{T}$ have a linear relationship. The detailed results are put in Table S2 S4 of the supporting information and the $G(\alpha)$ is listed in Table 7. It shows that $G(\alpha)$ for RDX crystal can be described by the Avrami-Erofeev equation with $n=3 / 4$, indicating that the decomposition process is controlled by random nucleation and subsequent growth ${ }^{14}$. However, the decomposition mechanism of RDX molecules in RDX(210)/Aloxide and 
$\mathrm{RDX}(210) / \mathrm{Al}_{2} \mathrm{O}_{3}(0001)$ complexes compares more favorable with the three dimensional diffusion model. This is due to the interfacial interaction between $\mathrm{RDX} / \mathrm{Al}$ that promotes reactive sites instead of random nucleation. Further research shows that Jander equation is fit for $\operatorname{RDX}(210) /$ Aloxide, while the Z-L-T equation is suitable for $\operatorname{RDX}(210) / \mathrm{Al}_{2} \mathrm{O}_{3}(0001)$. Liu et al ${ }^{16}$ found that the $\mathrm{G}(\alpha)$ all conforms to the Z-L-T equation whether the mass percentage of $\mu \mathrm{m}-\mathrm{Al}$ changes from $10 \%$ to $40 \%$ in RDX-based aluminized explosives. These results suggest that the modified ReaxFF creates a credible interface and the $\mathrm{RDX}(210) / \mathrm{Al}_{2} \mathrm{O}_{3}(0001)$ complex is able to represent $\mathrm{RDX} / \mu \mathrm{m}-\mathrm{Al}$ mixtures, as it entails to the chemical reactions occurring at the interfaces.

Table 7. The most probable kinetic model function $\mathrm{G}(\alpha)$ of RDX and RDX/Al complex using Šatava-Šesták equation

\begin{tabular}{|c|c|c|c|c|c|}
\hline Structure & $\begin{array}{c}\mathrm{E}_{\text {ozawa }} \\
\mathrm{kJ} / \mathrm{mol}\end{array}$ & $\begin{array}{c}\mathrm{E}_{\mathrm{s}} \\
\mathrm{kJ} / \mathrm{mol}\end{array}$ & $\begin{array}{l}\lg \mathrm{K}_{\mathrm{s}} \\
\mathrm{s}^{-1}\end{array}$ & $\mathrm{G}(\alpha)$ & Mechanism \\
\hline bulk RDX & 137.3 & 130 & 18.19 & {$[-\ln (1-\alpha)]^{3 / 4}$} & $\begin{array}{l}\text { Random nucleation and } \\
\text { subsequent growth }\end{array}$ \\
\hline $\begin{array}{c}\text { RDX(210)/ } \\
\text { Aloxide }\end{array}$ & 96.2 & 87.7 & 17.10 & {$\left[1-(1-\alpha)^{1 / 3}\right]^{2}$} & $\begin{array}{c}\text { three-dimensional } \\
\text { diffusion, symmetric } \\
\text { sphere, } \mathrm{D} 3 \text { decrease type } \\
\alpha-\mathrm{t} \text { curve, } \mathrm{n}=2\end{array}$ \\
\hline $\begin{array}{l}\mathrm{RDX}(210) / \\
\mathrm{Al}_{2} \mathrm{O}_{3}(0001)\end{array}$ & 156.7 & 154.37 & 16.48 & {$\left[(1-\alpha)^{-1 / 3}-1\right]^{2}$} & $\begin{array}{l}\text { Z-L-T equation, } \\
\text { three-dimensional diffusion }\end{array}$ \\
\hline
\end{tabular}

\subsection{Oxygen diffusion into $\mathrm{Al}$ and oxidization}

We use large-scale RMD simulations to provide detailed dynamic snapshots and a better understanding of the oxygen diffusion and oxidization processes, derived from RDX fragments and Al. Snapshots that capture this complicated process are shown in Figure 8 at a heating rate of $30 \mathrm{~K} / \mathrm{ps}$. Up to $40 \mathrm{ps}$, RDX molecules with enough kinetic energies, induced by linear thermal heating, occupy the space between RDX slab and Al slab. At $49.5 \mathrm{ps}$, the first decomposition of RDX molecules takes place at the interface between these two slabs, which proves that the probable kinetic mechanism is three-dimensional diffusion. The number of RDX molecules decays to zero at $70 \mathrm{ps}$. Then, oxygen atoms derive from decomposed RDX molecules, and gradually diffuse into oxidized Al slab layer, as seen from Figure 8(c).

The initial thickness of the left oxide layer of Al slab is about $9.2 \AA$ and that of the right oxide layer is $7.6 \AA$. As the temperature rises, RDX fragments continue to 
oxidize Al slab through the left oxide layer via three sequential steps ${ }^{85}$ : (i) insert into the left oxide layer, (ii) diffusion of oxygen through the thick oxide layer and (iii) oxidation at interface of $\mathrm{Al}$ and its oxide. However, the inner $\mathrm{Al}$ underneath the thinner oxide layer melts first and the oxide layer becomes coarse due to expansion pressure, as seen from Figure 8(d). A large number of RDX fragments containing oxygen, hydrogen or nitrogen atoms are now capable to diffuse into, and oxidize, inner $\mathrm{Al}$ atoms, which can be seen between $90 \mathrm{ps} \sim 170$ ps in Figure 8(e) (g).

(a) $40 \mathrm{ps}$

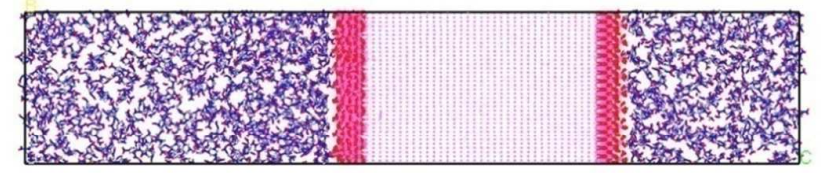

(b) $49.5 \mathrm{ps}$

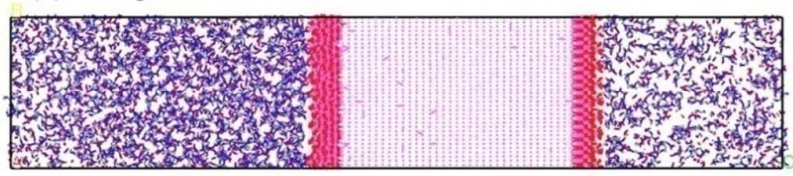

(c) $70 \mathrm{ps}$

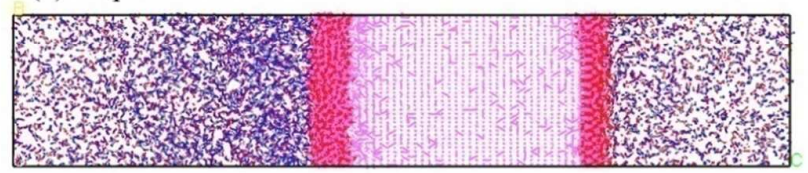

(d) $80 \mathrm{ps}$

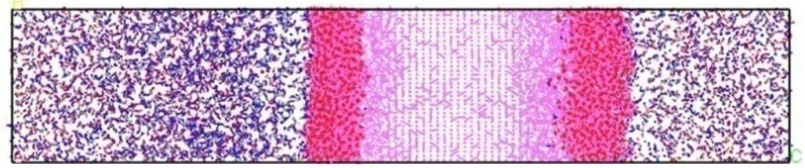

(e) $90 \mathrm{ps}$

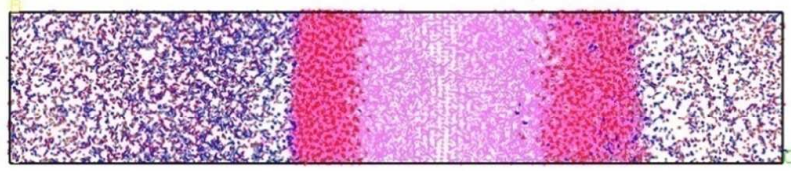

(f) $110 \mathrm{ps}$

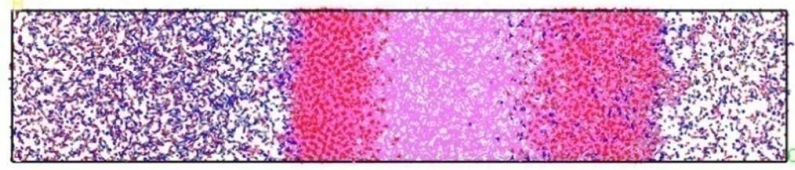

(g) $170 \mathrm{ps}$

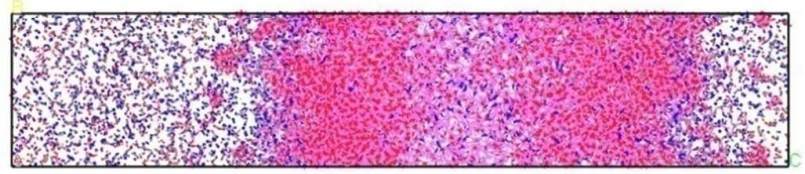

Figure 8. Snapshots of oxygen diffusion and oxidization of $\mathrm{Al}$ at a heating rate of $30 \mathrm{~K} / \mathrm{ps}$. Color scheme: Red, oxygen; magenta, aluminum; blue, nitrogen; gray, carbon; white, hydrogen.

In order to quantitatively describe the process on oxygen diffusion into $\mathrm{Al}$ slab, we 
calculated the self-diffusion coefficient $\left(D_{s}\right)$ of oxygen atoms in RDX molecules and oxidized layer of Al surface. Figure 9 shows the mean-squared displacement (MSD) of RDX molecules along the dz direction in RDX crystal and the three types of $\mathrm{RDX} / \mathrm{Al}$ models at a heating rate of $30 \mathrm{~K} / \mathrm{ps}$. Given that the simulation box in the $\mathrm{dx}$ and dy directions is periodic, we only focus on the dz direction. The slope of the MSD versus time is proportional to the self-diffusion coefficient $\left(D_{s}\right)$ of the oxygen atoms. In Figure 9(a), the $D_{s}$ is $4.2 \times 10^{-7} \mathrm{~cm}^{2} / \mathrm{s}$ before RDX molecules decompose while it changes into $8.87 \times 10^{-5} \mathrm{~cm}^{2} / \mathrm{s}$ after RDX molecules are completely decomposed, indicating that oxygen atoms in RDX fragments move easier than those in RDX molecules. At the initial stage in Figure 9(b) $\sim 9(\mathrm{~d})$, the linear MSD along the $\mathrm{dz}$ direction belongs to diffusion of RDX molecules onto the surface of Al slab. After the number of RDX molecules decays, the MSD of oxygen atoms attached to RDX fragments can be described by a linear fit as a function of time. Thus, the $D_{s}$ is $4.75 \times 10^{-4} \mathrm{~cm}^{2} / \mathrm{s}$ in $\operatorname{RDX}(210) /$ Aloxide and $3.1 \times 10^{-4} \mathrm{~cm}^{2} / \mathrm{s}$ in $\operatorname{RDX}(210) / \mathrm{Al}(111)$ with a linear regression coefficient of 0.99 . The fast $\mathrm{D}_{\mathrm{s}}$ in $\operatorname{RDX}(210) /$ Aloxide allows oxygen atoms into the inner $\mathrm{Al}$ slab. Because of the oxidation of $\mathrm{Al}(111)$ by decomposed RDX fragments at the initial stage, a more complicated oxide layer forms, which contains five elements. This is less unfavorable for the diffusion of oxygen atoms into $\mathrm{Al}$ slab in $\mathrm{RDX}(210) / \mathrm{Al}(111)$ than that in $\mathrm{RDX}(210) /$ Aloxide.

The $\mathrm{D}_{\mathrm{s}}$ of oxygen atoms of RDX fragments is $1.9 \times 10^{-4} \mathrm{~cm}^{2} / \mathrm{s}$ in $\mathrm{RDX}(210) / \mathrm{Al}_{2} \mathrm{O}_{3}(0001)$. We also calculated the MSD of oxygen atoms in Aloxide and $\mathrm{Al}_{2} \mathrm{O}_{3}(0001)$ slab, respectively. The small MSD at the initial stage $(\sim 120 \mathrm{ps})$ shows that both Aloxide slab and $\mathrm{Al}_{2} \mathrm{O}_{3}(0001)$ slab remain intact during the decomposition of RDX molecules. Subsequently, it is $1.65 \times 10^{-4} \mathrm{~cm}^{2} / \mathrm{s}$ for oxygen atoms in Aloxide slab and $3.5 \times 10^{-5} \mathrm{~cm}^{2} / \mathrm{s}$ for those in $\mathrm{Al}_{2} \mathrm{O}_{3}(0001)$ slab. It indicates that the oxygen atoms from decomposed $\mathrm{RDX}$ are less diffusive in the $\mathrm{Al}_{2} \mathrm{O}_{3}$ slab and $\mathrm{Al}_{2} \mathrm{O}_{3}$ slab is inert during the thermal decomposition of RDX.
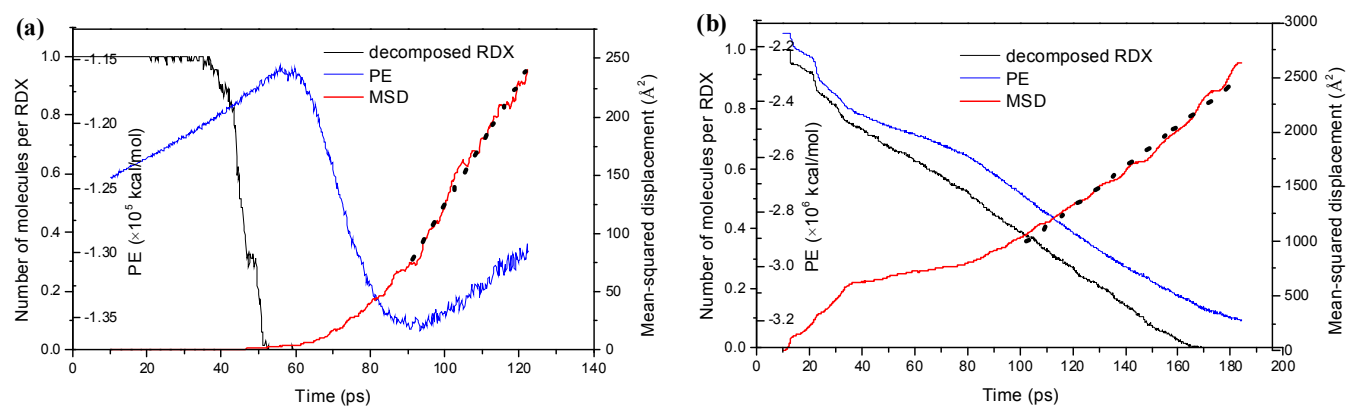

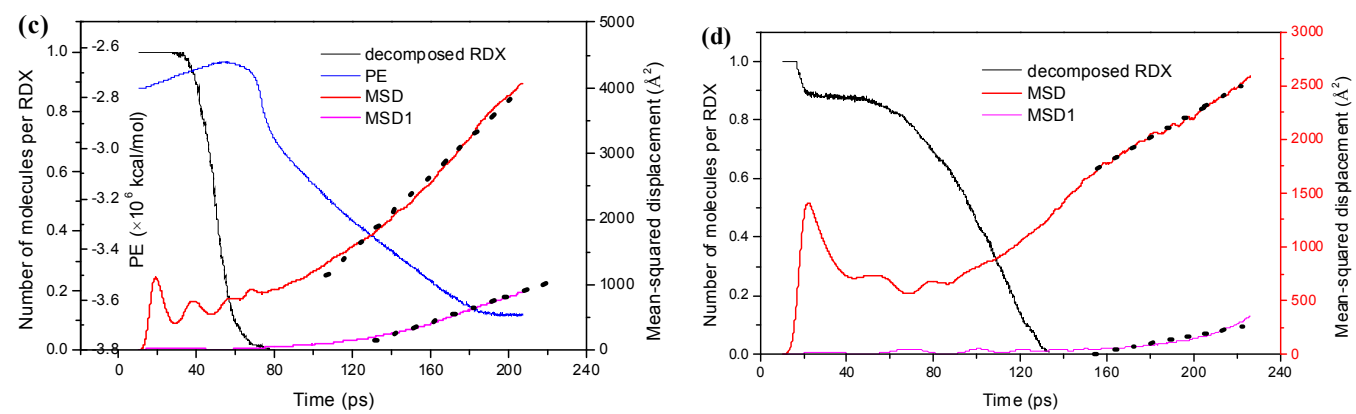

Figure 9. Mean-squared displacement of oxygen atoms in RDX molecules along the $\mathrm{Z}$ direction ("MSD", red lines) as a function of time for $\mathrm{RDX}(\mathrm{a}), \operatorname{RDX}(210) / \mathrm{Al}(111)(\mathrm{b}), \operatorname{RDX}(210) / \operatorname{Aloxide}(\mathrm{c})$ and $\mathrm{RDX}(210) / \mathrm{Al}_{2} \mathrm{O}_{3}(0001)(\mathrm{d})$. Mean-squared displacements of oxygen atoms in Aloxide(c) and $\mathrm{Al}_{2} \mathrm{O}_{3}(0001)(\mathrm{d})$ are also presented with ("MSD1", magenta lines). The time evolution of the number of decomposed RDX molecules (“decomposed RDX”, black lines) and potential energy ("PE", blue lines) are shown in black and green lines, which is helpful for understanding the oxygen diffusion process.

\subsection{Evolution of chemical species}

ReaxFF is able to describe bond breaking and formation during dynamic simulations, so it is often employed in the study of initial reactive pathways and evolution of chemical species. Figure 10 shows the concentration of $\mathrm{NO}_{2}$ and $\mathrm{HONO}$ per RDX molecule from the RDX and RDX/Al model systems, which are the two primary competing reaction mechanisms of RDX molecules. From the initial decomposition time and concentration, it shows that $\mathrm{NO}_{2}$ dominates with respect to HONO. For RDX(210)/Aloxide complex, $\mathrm{NO}_{2}$ appears earlier and the concentration is over three times larger than that for the bare RDX crystal, which results in subsequent fast reactions. $\mathrm{NO}_{2}$ and $\mathrm{HONO}$ increase slowly in $\mathrm{RDX}(210) / \mathrm{Al}_{2} \mathrm{O}_{3}(0001)$ complex, indicating that the presence of $\mathrm{Al}_{2} \mathrm{O}_{3}(0001)$ may retard thermal decomposition of RDX. The concentrations of $\mathrm{NO}_{2}$ and HONO in RDX(210)/Al(111) are very low and instead other species such as $\mathrm{N}_{2}, \mathrm{C}_{2} \mathrm{H}_{4} \mathrm{~N}, \mathrm{CHN}$ and $\mathrm{CN}$ appear at the very initial stage. This is due to the decrease of oxygen atoms, which in turn makes breaking the concerted ring easier. 

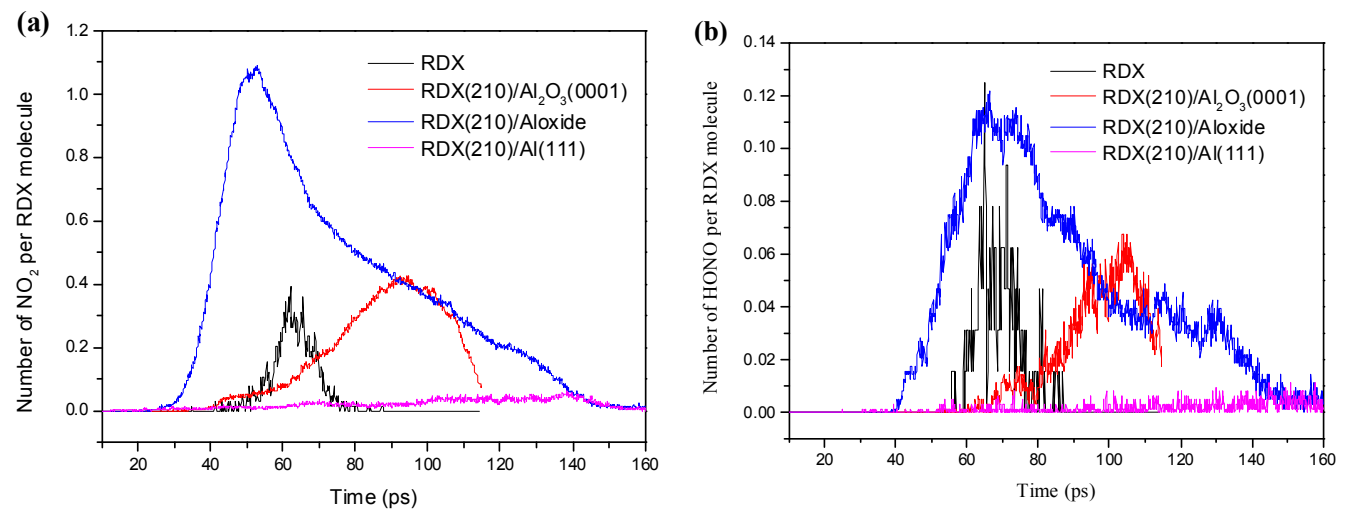

Figure 10. The time evolution of dissociated $\mathrm{NO}_{2}$ (a) and HONO (b) per RDX molecule at a heating rate of $40 \mathrm{~K} / \mathrm{ps}$.

Reaching thermal equilibrium for the oxidization of $\mathrm{Al}$ takes a long time at slow heating rates, so we analyzed the population of key species in the gas phase and the clusters in the condensed phase, at a heating rate of $140 \mathrm{~K} / \mathrm{ps}$. This may be a quasi-equilibrium state, but we believe that it is of significance and provides sufficient information to compare the difference in components between RDX and the three $\mathrm{RDX} / \mathrm{Al}$ model complexes under the same conditions. Table 8 shows the population of key species in the quasi-equilibrium at a certain time. Most of these species were detected by DSC-TG-MS-FTIR for neat RDX and RDX/Al mixtures. ${ }^{15}$ Carbon element exists in the form of gaseous $\mathrm{CO}_{2}$ for RDX crystal, but gaseous $\mathrm{CO}$ and $\mathrm{C}-\mathrm{N}$ fragments cannot be ignored in the RDX/Al complex. Similarly, $\mathrm{H}$ element exists in the form of $\mathrm{H}_{2} \mathrm{O}$ for RDX crystal, but there are also a great many of other fragments containing $\mathrm{H}$ such as $\mathrm{HO}$ and $\mathrm{H}_{2}$ in RDX/Al complex. We note that the fragments containing $\mathrm{C}$ in gas phase are relatively less in $\operatorname{RDX}(210) / \operatorname{Al}(111)$ than those in the other two systems. These phenomena result from lack of oxygen atoms, which have partly diffused into the inner Al slab. Otherwise, the total population of key fragments in $\mathrm{RDX}(210) / \mathrm{Al}(111)$ and $\mathrm{RDX} /$ Aloxide are less than that in $\mathrm{RDX}(210) / \mathrm{Al}_{2} \mathrm{O}_{3}(0001)$, which is attributed to the loss of the number of three elements in gas phase and the participation in the oxidization of $\mathrm{Al}$ slab. Comparing $\mathrm{RDX}(210) / \mathrm{Al}_{2} \mathrm{O}_{3}(0001)$ with RDX, we observe that apart from the main decomposition products of RDX molecules including $\mathrm{CO}_{2}, \mathrm{~N}_{2}$ and $\mathrm{H}_{2} \mathrm{O}$, there are also many intermediate fragments such as ring-breakage fragments ( $\mathrm{CN}$ complex) and unstable species (HO). As there aren't enough coordinates for $\mathrm{C}, \mathrm{H}$ and $\mathrm{N}$ elements in $\mathrm{Al}_{2} \mathrm{O}_{3}$ slab, these intermediate fragments need a long time to undergo series of secondary reactions. 
Table 8. Population of key fragments in the quasi-equilibrium at a heating rate of $140 \mathrm{~K} / \mathrm{ps}$

\begin{tabular}{|c|c|c|c|c|c|}
\hline Species & $\begin{array}{c}\text { RDX* } \\
\text { At 35ps }\end{array}$ & $\begin{array}{c}\text { RDX/Al } \mathrm{O}_{3} \\
\text { At 84ps }\end{array}$ & $\begin{array}{c}\text { RDX/Aloxide } \\
\text { At 74ps }\end{array}$ & $\begin{array}{c}\text { RDX/Al(111) } \\
\text { At 74ps }\end{array}$ & Exp. $^{15}$ \\
\hline $\mathrm{CO}$ & 0 & 381 & 263 & 42 & $\checkmark$ \\
\hline $\mathrm{CO} 2$ & 34 & 290 & 54 & 25 & $\checkmark$ \\
\hline $\mathrm{N} 2$ & 97 & 1098 & 424 & 695 & $\checkmark$ \\
\hline $\mathrm{CN}$ & 1 & 336 & 142 & 55 & $\checkmark$ \\
\hline $\mathrm{CHN}$ & 2 & 155 & 76 & 19 & $\checkmark$ \\
\hline $\mathrm{CHNO}$ & 0 & 127 & 13 & 17 & $\checkmark$ \\
\hline $\mathrm{CHO}$ & 0 & 32 & 26 & 0 & $\checkmark$ \\
\hline $\mathrm{H}_{2} \mathrm{~N}$ & 1 & 98 & 44 & 29 & $\checkmark$ \\
\hline $\mathrm{H}_{2} \mathrm{O}$ & 45 & 742 & 173 & 208 & $\checkmark$ \\
\hline $\mathrm{HO}$ & 6 & 411 & 95 & 185 & $\checkmark$ \\
\hline $\mathrm{H}_{2}$ & 0 & 134 & 113 & 68 & N.A. \\
\hline $\mathrm{H}$ & 0 & 73 & 87 & 104 & N.A. \\
\hline $\mathrm{O}_{2}$ & 4 & 101 & 18 & 50 & N.A. \\
\hline $\mathrm{O}$ & 1 & 43 & 32 & 90 & N.A. \\
\hline
\end{tabular}

*The initial number of RDX molecules is 64 for pure RDX crystal and 640 for the three RDX/Al model complexes.

The type and population of condensed species would normally provide the necessary data to analyze the gas phase results albeit not in a straightforward manner. Therefore, we chose the largest cluster to analyze the ingredients of residues containing Al. Figure 11 shows the content of five elements in the maximum cluster at a heating rate of $140 \mathrm{~K} / \mathrm{ps}$, which is also in the quasi-equilibrium state at the end of RMD simulations. There is a large amount of C and H elements in RDX(210)/Al(111) are more than those found in $\mathrm{RDX}(210)$ /Aloxide. The concentration of $\mathrm{CO}$ and $\mathrm{CO}_{2}$ in gas phase for $\operatorname{RDX}(210) / \operatorname{Al}(111)$ is also lower than that in $\operatorname{RDX}(210) /$ Aloxide. This is due to active fragments are prone to spread into inner Al slab without the restraint of oxide layer in $\mathrm{RDX}(210) / \mathrm{Al}(111)$. For $\mathrm{RDX}(210) / \mathrm{Al}_{2} \mathrm{O}_{3}(0001)$, the content of $\mathrm{C}, \mathrm{H}$ and $\mathrm{N}$ elements can be ignored and the ratio of $\mathrm{Al}$ to $\mathrm{O}$ is 0.58 . This confirms once again that $\mathrm{Al}_{2} \mathrm{O}_{3}$ doesn't participate in the decomposition of $\mathrm{RDX}$ molecules, aside from interactions caused by $\mathrm{Al}$ atoms at the surface. 


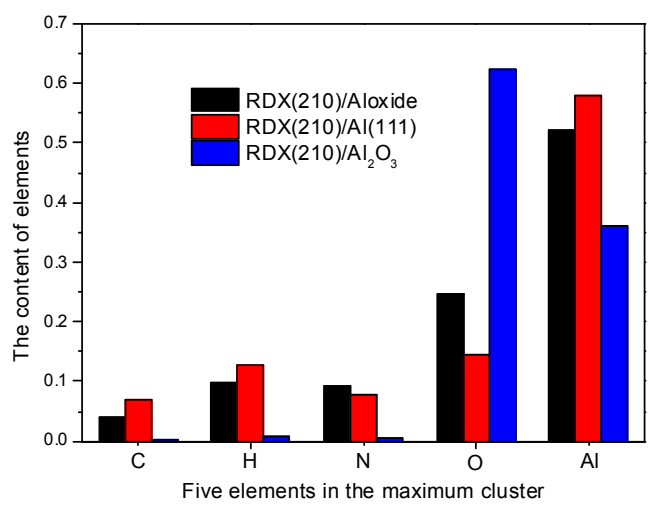

Figure 11. The content of five elements in the maximum cluster at a heating rate of $140 \mathrm{~K} / \mathrm{ps}$.

\section{Conclusion}

We have produced a new ReaxFF reactive force field for aluminum and RDX interactions, based on previously published parameters for $\mathrm{Al}^{33,47-49}, \mathrm{C}, \mathrm{H}, \mathrm{N}$ and $\mathrm{O}^{39}$, and bond information from $\mathrm{Al}-\mathrm{H},{ }^{58}$ and crystal parameters from $\mathrm{Al}-\mathrm{C},{ }^{60}$ and $\mathrm{Al}-\mathrm{N} .{ }^{61}$ The modified ReaxFF provides a good descriptions of crystal constants, bulk modulus, cohesive energies and EOS curves of various crystal phases and a large number of cluster conformations, thanks to the global optimization strategy employed. ${ }^{40}$ The obtained force field was validated against test cases not included in the training set, including surface energies, chemical adsorption energies of one RDX molecule on $\mathrm{Al}(111)$ surface and oxidation of bare $\mathrm{Al}(431)$. All of these results are in close agreement with DFT calculations, which confirms the good predictive capabilities of the new ReaxFF force field.

We applied this force field and RMD to demonstrate different interfacial properties between RDX and Al (with and without oxide layers), all of which are in good agreement with experimental results, including apparent activation energy, the most probable kinetic model function and evolution of chemical species in gas phase.

Similar with thermal analytical techniques, we obtained the non-isothermal decomposition kinetics. The thermal decomposition of pure RDX crystal is controlled by random nucleation and subsequent growth and that of $\mathrm{RDX} / \mathrm{Al}$ complexes is more favorable with the three-dimensional diffusion model.

Meanwhile, large-scale RMD simulations provide enhanced details for understanding the static and time-dependent effects of nano-sized Al on thermal decomposition of $\alpha$-RDX. At the nucleation stage, the initial reaction easily happens at the $\mathrm{RDX} / \mathrm{Al}$ interface due to the strong interaction between $\mathrm{Al}$ and other four 
elements. At the subsequent growth stage, whether the chain reaction happens or not is decided by the feedback of energy and active fragments. From the low decomposition rate in $\mathrm{RDX} / \mathrm{Al}(111)$ model, low concentration of $\mathrm{CO}$ and $\mathrm{CO}_{2}$ species in gas phase and relative high $\mathrm{C}$ elements in condensed phase, it shows that active fragments of decomposition are prone to spread into inner Al slab. This is because the $\mathrm{Al}(111)$ surface-assisted decomposition of RDX occurs spontaneously without potential barriers. However, a $1 \mathrm{~nm}$ thick oxide layer on Al surface not only enhances the concentration of $\mathrm{NO}_{2}$ and $\mathrm{HONO}$, restrains the spread of fragments, but also goes on the oxidation of $\mathrm{Al}$ exposed to $\mathrm{RDX}$ molecules to release energy, which can be seen from the history of potential energy. These result in the rapid decomposition of RDX followed oxidation of inner Al. Although one Al-terminated layer on $\alpha-\mathrm{Al}_{2} \mathrm{O}_{3}(0001)$ surface induce about $12 \%$ percent of RDX molecules decomposed, the energy is partly consumed by thermal expansion of $\mathrm{Al}_{2} \mathrm{O}_{3}$ and the long induction period exists in the decomposition process of surplus RDX molecules. Therefore, $\alpha-\mathrm{Al}_{2} \mathrm{O}_{3}(0001)$ retards thermal decomposition of $\mathrm{RDX}$.

The meaningful reaction details in RDX/Al interface are qualitatively disclosed by RMD simulations, but there are still lots of work needed to provide the reaction pathways and reaction energies for the key reactions of these mechanisms in RDX/Al interface, which shows obvious difference from RDX crystal by this work. Further work would focus on the effect of structure of oxide layer on Al slab and the ratio of Al to RDX on thermal decomposition of RDX.

Associated content

The force field parameters and further details on its validation including: dissociation energy profiles of various bonds and angles, initial and adsorption configurations of $\mathrm{RDX} / \mathrm{Al}(111)$, kinetic model functions and kinetic parameters at different heating rate for RDX and RDX/Al complex, and others are included in the supporting information available free of charge on the ACS publications website.

\footnotetext{
Author information

Corresponding authors

*E-mail: pengjh@njust.edu.cn.
}

Author Contributions 
$\S$ N. W., J. H. P. and A.J. B. contributed equally to this work; they performed and analyzed the simulation.

Notes

The authors declare no competing financial interests.

\section{Acknowledgments}

We thank Dr. Jianjiang Hu for many useful discussion and careful revision of the whole manuscript. We acknowledge funding support from WEP under the contract 6140656020205. Computations in this work were carried out in the Supercomputer Center of the fourth academy of CASC, P. R. China.

\section{References}

(1) Arkhipov, V. I.; Makhov, M. N.; Pepekin, V. I.; Shchetinin, V. G. Investigations into Detonation of Aluminized High Explosives. Chem. Phys. Rep. 2000, 18(12), 2329-2337.

(2) Kumar, A. S.; Rao, V. B.; Sinha, R. K.; Rao, A. S. Evaluation of Plastic Bonded Explosive (PBX) Formulations Based on RDX, Aluminum, and HTPB for Underwater Applications. Propell. Explos. Pyrot. 2010, 35(4), 359-364.

(3) Vadhe, P. P.; Pawar, R. B.; Sinha, R. K.; Asthana, S. N.; Rao, A. S. Cast Aluminized Explosives. Combust. Explos. Shock waves 2008, 44(4), 461-477.

(4) Gogulya, M. F.; Makhov, M. N.; Dolgoborodov, A. Y.; Brazhnikov, M. A.; Arkhipov, V. I.; Shchetinin, V. G. Mechanical Sensitivity and Detonation Parameters of Aluminized Explosives. Combust. Explos. Shock waves 2004, 40(4), 445-457.

(5) Lewis, W. K.; Rumchik, C. G.; Broughton, P. B.; Lindsay, C. M. Time-resolved Spectroscopic Studies of Aluminized Explosives: Chemical Dynamics and Apparent Temperatures. J. Appl. Phys. 2012, 111(1), 461.

(6) Manner, V. W.; Pemberton, S. J.; Gunderson, J. A.; Herrera, T. J.; Lloyd, J. M.; Salazar, P. J.; Rae, p.; Tappan, B. C. The Role of Aluminum in the Detonation and Post-detonation Expansion of Selected Cast HMX-based Explosives. Propell. Explos. Pyrot. 2012, 37(2), 198-206.

(7) Gogulya, M. F.; Makhov, M. N.; Brazhnikov, M. A.; Dolgoborodov, A. Y.; Arkhipov, V. I.; Zhigach, A. N.; Leipunskii, I. O.; Kuskov, M. L. Explosive Characteristics of Aluminized HMX-based Nanocomposites. Combust. Explos. Shock waves 2008, 44(2), 198-212.

(8) Huang, H.; Huang, H. J.; Huang, Y.; Wang, X. C. Influence of Aluminum Particle Size and Oxidizer Morphology in RDX-based Aluminized Explosives on Their Ability to Accelerate Metals. Explos. Shock Waves 2006, 26(1), 7-11.

(9) Wang, S. P.; Feng, X. S.; Yao, L. N.; Niu, G. T.; Chao, S. T.; Niu, L. The Influence of Nanometer Aluminum on the Explosion Heat of RDX-based Explosive. Initiators Pyrotech. 2014, (1), 21-24.

(10) Niu, G. T.; Wang, S. P.; Jin, D. Y.; Niu, L.; T., C. S. Influence of the Nano-aluminium on Underwater Energy of RDX-based Explosives. Chin. J. Explos. Propellants 2015, 38(1), 64-68.

(11) Wang, H.; Shen, F. Effect of Active Aluminum Powder on the Driving Ability of RDX-based Aluminized Explosive. Sci. Tech. Engrg. 2016, 16(3), 1671-1815. 
(12) Miao, Q. S.; Xu, G. G.; Wang, T. Z. Mechanism analysis of the influence of Al shape and size on the detonation properties of Aluminized explosives. Chin. J. Explos. Propellants 2002, 25(2), 4-6.

(13) Storm, C. B.; Stine, J. R.; Kramer, J. F. Sensitivity Relationship in Energetic Materials in Chemistry and Physics of Energetic Materials. Kluwer Academic Publishers, Dordrecht 1990,

(14) Huang, H.; Jiao, Q. J.; Li, J. L.; Zhu, X. D.; Zang, C. G. Effect of Aluminum Particle Size on the Thermal Decomposition of RDX. Chin. J. Explos. Propellants 2011, 34(6), 48-52.

(15) Zhu, Y. L.; Huang, H.; Ren, H.; Jiao, Q. J. Influence of Aluminum Particle Size on Thermal Decomposition of RDX. J. Energ. Mater. 2013, 31(3), 178-191.

(16) Liu, R.; Yang, L.; Zhou, Z. N.; Zhang, T. L. Thermal Stability and Sensitivity of RDX-based Aluminized Explosives. J. Therm. Anal. Calorim. 2014, 115, 1939-1948.

(17) Chakraborty, D.; Muller, R. P.; Dasgupta, S.; Goddard, W. A., III The Mechanism for Unimolecular Decomposition of RDX (1,3,5-trinitro-1,3,5-triazine), an Ab Initio Study. J. Phys. Chem. A 2000, 104, 2261-2272.

(18) Irikura, K. K. Aminoxyl (Nitroxyl) Radicals in the Early Decomposition of the Nitramine RDX. J. Phys. Chem.A 2013, 117, 2233-2241.

(19) Kuklja, M. M. Thermal Decomposition of Solid Cyclotrimethylene Trinitramine. J. Phys. Chem.B 2001, 105, 10159-10162.

(20) Schweigert, I. V. Ab Initio Molecular Dynamics of High-temperature Unimolecular Dissociation of Gas-phase RDX and Its Dissociation Products. J. Phys. Chem. A 2015, 119, 2747-2759.

(21) Strachan, A.; Kober, E. M.; van Duin, A. C. T.; Oxgaard, J.; Goddard, W. A., III Thermal Decompostion of RDX from Reactive Molecular Dynamics. J. Chem. Phys. 2005, 122(5), 054502.

(22) Miao, M. S.; Dreger, Z. A.; Patterson, J. E.; Gupta, Y. M. Shock Wave Induced Decomposition of RDX: Quantum Chemistry Calculations. J. Phys. Chem.A 2008, 112, 7383-7390.

(23) Nomura, K.; Kalia, R. K.; Nakano, A.; Vashishta, P.; van Duin, A. C. T.; Goddard, W. A., III Dynamic Transition in the Structure of an Energetic Crystal During Chemical Reactions at Shock Front prior to Detonation. Phys. Rev. Lett. 2007, 99(148303),

(24) Strachan, A.; van Duin, A. C. T.; Chakraborty, D.; Dasgupta, S.; Goddard, W. A., III Shock Waves in High-energy Materials: the Initial Chemical Events in Nitramine RDX. Phys. Rev. Lett. 2003, 91(9), 098301.

(25) Clark, R.; Wang, W.; Nomura, K.; Kalia, R.; Nakano, A.; Vashishta, P. In Heat-initiated Oxidation of an Aluminum Nanoparticle. proceedings of the MRS Meeting, Boston, MA, Nov. 25-30 2012,

(26) Campbell, T. J.; Aral, G.; Ogata, S.; Kalia, R. K.; Nakano, A.; Vashishta, P. Oxidation of Aluminum Nanoclusters. Phys. Rev. B: Condens. Matter Mater. Phys. 2005, 71, 205413.

(27) Jeurgens, L. P. H.; Sloof, W. G.; Tichelaar, F. D.; Mittemeijer, E. J. Structure and Morphology of Aluminum-oxide Films Formed by Thermal Oxidation of Aluminum. Thin Solid Films 2002, 418(2), 89-101.

(28) Levin, I.; Brandon, D. Metastable Alumina Polymorphs: Crystal Structures and Transitions Sequences. J. Am. Ceram. Soc. 1998, 81,

(29) Steinheil, A. The Structure and Growth of Thin Surface Films on Metals on Oxidation in Air. Ann. Phys. 1934, 19(465),

(30) Jeurgens, L.; Sloof, W.; Tichelaar, F.; Mittemeijer, E. Growth Kinetics and Mechanisms of Aluminum-Oxide Films Formed by Thermal Oxidation of Aluminum. J. Appl. Phys. 2002, 92, 1649-1656. (31) Sánchezlópez, J. C.; Gonzálezelipe, A. R.; Fernández, A. Passivation of Nanocrystalline Al Prepared by the Gas Phase Condensation Method: an X-ray Photoelectron Spectroscopy Study. J. Mater. Res. 
1998, 13(3), 703-710.

(32) Jeurgens, L. P. H.; Sloof, W. G.; Tichelaar, F. D.; Mittemeijer, E. J. Thermodynamic Stability of Amorphous Oxide Films on Metals: Application to Aluminum Oxide Films on Aluminum Substrates. Phys. Rev. B 2000, 62, 4707.

(33) Hong, S.; van Duin, A. C. T. Molecular Dynamics Simulations of the Oxidation of Aluminum Nanoparticles Using the ReaxFF Reactive Force Field. J. Phys. Chem. C 2015, 119, 17876-17886.

(34) Umezawa, N.; Kalia, R. K.; Nakano, A.; Vashishta, P.; Shimojo, F. 1,3,5-trinitro-1,3,5-triazine Decompostion and Chemisorption on Al(111) Surface: First-principles Molecular Dynamics Study. J. Chem. Phys. 2007, 126, 234702.

(35) Ye, C. C.; Zhao, F. Q.; Xu, Z. S.; Ju, X. H. Adsorption and Decomposition Mechanism of Hexogen (RDX) on Al(111) Surface by Periodic DFT Calculations. J. Mol. Model. 2013, 19, 2451-2458.

(36) Guadarrama-Pérez, C.; Martínez de La Hoz, J. M.; Balbuena, P. B. Theoretical Infrared and Terahertz Spectra of an RDX/Aluminum Complex. J. Phys. Chem. A 2010, 114, 2284-2292.

(37) Martínez de La Hoz, J. M.; Balbuena, P. B. Vibrational Spectra of an RDX Film over an Aluminum Substrate from Molecular Dynamics Simulations and Density Functional Theory. J. Mol. Model. 2013, 19, 2773-2778.

(38) Senftle, T. P.; Hong, S.; Islam, M. M.; Kylasa, S. B.; Zheng, Y.; Shin, Y. K.; Junkermeier, C.; Engel-Herbert, R.; Janik, M. J.; Aktulga, H. M., et al. The ReaxFF Reactive Force-field: Development, Applications and Future Directions. npj Comput. Mater. 2016, 2, 15011.

(39) Wood, M. A.; van Duin, A. C. T.; Strachan, A. Coupled Thermal and Electromagnetic Induced Decomposition in the Molecular Explosive $\alpha \mathrm{HMX}$; a Reactive Molecular Dynamics Study. J. Phys. Chem. A 2014, 118, 885-895.

(40) Jaramillo-Botero, A.; Naserifar, S.; Goddard, W. A., III General Multiobjective Force Field Optimization Framework, with Application to Reactive Force Fields for Silicon Carbide. J. Chem. Theory Comput. 2014, 10, 1426-1439.

(41) Segall, M. D.; Lindan, P. J. D.; Probert, M. J.; Pickard, C. J.; Hasnip, P. J.; Clark, S. J.; Payne, M. C. First-principles Simulation: Ideas, Illustrations and the CASTEP Code. J. Phys.: Condens. Matter 2002, 14, 2717-2743.

(42) Perdew, J. P.; Burke, K.; Ernzerhof, M. Generalized Gradient Approximation Made Simple. Phys. Rev. Lett. 1996, 77, 3865-3868.

(43) Kresse, G.; Furthmuller, J. Efficient Iterative Schemes for Ab Initio Total-energy Calculations Using a Plane-wave Basis Set. Phys. Rev. B 1996, 54, 11169-11186.

(44) Pfrommer, B. G.; Cote, M.; G., L. S.; Cohen, M. L. Relaxation of Crystals with the Quasi-newton Method. J. Comput. Phys. 1997, 131, 133-140.

(45) Plimpton, S. Fast Parallel Algorithms for Short-range Molecular Dynamics. J. Chem. Phys. 1995, 117, 1-19.

(46) van Duin, A. C. T.; Dasgupta, S.; Lorant, F.; Goddard, W. A., III ReaxFF: a Reactive Force Field for Hydrocarbons. J. Phys. Chem. A 2001, 105, 9396-9409.

(47) Narayanan, B.; Van Duin, A. C. T.; Kappes, B. B.; Reimanis, I. E.; Ciobanu, C. V. A Reactive Force Field for Lithium-aluminum Silicates with Applications to Eucryptite Phases. Modelling Simul. Mater. Sci. Eng. 2012, 20, 015002.

(48) Zhang, Q.; Çaĝın, T.; van Duin, A. C. T.; Goddard, W. A., III; Qi, Y.; Hector, L. G., Jr Adhesion and Nonwetting-wetting Transition in the $\mathrm{Al} / \alpha-\mathrm{Al}_{2} \mathrm{O}_{3}$ Interface. Phys. Rev. B 2004, 69, 045423.

(49) Valega Mackenzie, F. O.; Thijsse, B. J. Study of Metal/Epoxy Interfaces Between Epoxy Precursors 
and Metal Surfaces Using a Newly Developed Reactive Force Field for Alumina-amine Adhesion. J. Phys. Chem. C 2015, 119, 4796-4804.

(50) Chenoweth, K.; van Duin, A. C. T.; Goddard, W. A. III. ReaxFF Reactive Force Field for Molecular Dynamics Simulations of Hydrocarbon Oxidation. J. Phys. Chem. A 2008, 112, 1040-1053.

(51) Anderson, W. R.; Conner, C. B. Comparison of Gas-phase Mechanisms Applied to RDX Combustion Model. Proc. Combust. Inst. 2009, 32, 2123-2130.

(52) Shan, T. R.; Wixom, R. R.; Mattsson, A. E.; Thompson, A. P. Atomistic Simulation of Orientation Dependence in Shock-induced Initiation of Pentaerythritol Tetranitrate. J. Phys. Chem. B 2013, 117(3), 928-936.

(53) Wood, M. A.; Cherukara, M. J.; Kober, E. M.; Steinheil, A. Ultrafast Chemistry under Nonequilibrium Conditions and the Shock to Deflagration Transition at the Nanoscale. J. Phys. Chem. C 2015, 119, 22008-22015.

(54) Zhang, L. Z.; Zybin, S. V.; van Duin, A. C. T.; Dasgupta, S.; Goddard, W. A., III Carbon Cluster Formation During Thermal Decomposition of Octahydro-1,3,5,7-tetranitro-1,3,5,7-tetrazocine and 1,3,5-triamino-2,4,6-trinitrobenzene High Explosives from ReaxFF Reactive Molecular Dynamics Simulations. J. Phys. Chem. A 2009, 113, 10619-10640.

(55) DeLuca, L. T.; Galfetti, L.; Colombo, G.; Maggi, F.; Bandera, A.; Babuk, V. A.; Sinditskii, V. P. Microstructure Effects in Aluminized Solid Rocket Propellants. J. Propul. Power 2010, 26(4), 724-733.

(56) Il'in, A. P.; Yablunovskii, G. V.; Gromov, A. A. Influence of Additives on Combustion of Ultradisperse Aluminum Powder and Chemical Binding of Air Nitrogen. Combust. Explos. Shock waves 1996, 32(2), 211-213.

(57) Streletskii, A. N.; Povstugar, I. V.; Borunova, A. B.; Lomaeva, S. F.; Butyagin, P. Y. Mechanochemical Activation of Aluminum. 4. Kinetics of Mechanochemical Synthesis of Aluminum Carbide. Colloid J. 2006, 68(4), 470-480.

(58) Ojwang, J. G. O.; van Santen, R. A.; Kramer, G. J.; Van Duin, A. C. T.; Goddard, W. A., III Parametrization of a Reactive Force Field for Aluminum Hydride. J. Chem. Phys. 2009, 131, 044501.

(59) Turley, J. W.; Rinn, H. W. The Crystal Structure of Aluminum Hydride. Inorg. Chem. 1968, 8(1), 18-22.

(60) Xu, Y. N.; Ching, W. Y. Electronic, Optical, and Structural Properties of Some Wurtzite Crystals. Phys. Rev. B: Condens. Matter Mater. Phys. 1993, 48(7), 4335-4351. Data is also seen in ICSD-AIN-19939011657 and AIN-1963-9008860.

(61) Jeffrey, G. A.; Wu, V. Y. The Structure of the Aluminum Carbonitrides. II. Acta. Cryst. 1966, 20, 538-547. Data was also seen in ICSD \#14397 and \#66751.

(62) Larsson, H. R.; Van Duin, A. C. T.; Hartke, B. Global Optimization of Parameters in the Reactive Force Field ReaxFF for SiOH. J. Comput. Chem. 2013, 34, 2178-2189.

(63) An, Q.; Liu, Y.; Zybin, S. V.; Kim, H.; Goddard, W. A., III Anisotropic Shock Sensitivity of Cyclotrimethylene Trinitramine(RDX) from Compress-and-shear Reactive Dynamics. J. Phys. Chem. C 2012, 116, 10198-10206.

(64) Dang, N. C.; Dreger, Z. A.; Gupta, Y. M.; Hooks, D. E. Time-resolved Spectroscopic Measurements of Shock-wave Induced Decomposition in Cyclotrimethylene Trinitramine (RDX) Crystals: Anisotropic Response. J. Phys. Chem. A 2010, 114, 11560-11566.

(65) Wang, N.; Peng, J. H.; Pang, A. M.; Hu, J. J.; He, T. S. Study on the Anisotropic Response of Condensed-phase RDX under Repeated Stress Wave Loading via ReaxFF Molecular Dynamics Simulation. J. Mol. Model. 2016, 22, 229. 
(66) Doherty, P. E.; Davis, R. S. Direct Observation of the Oxidation of Aluminum Single-cristal Surfaces. J. Appl. Phys. 1963, 34, 619.

(67) Tomas, K.; Roberts, M. W. Direct Observation in the Electron Microscope of Oxide Layers on Aluminum. J. Appl. Phys. 1961, 32, 70.

(68) Steinheil, A. The Structure and Growth of Thin Surface Films on Metals on Oxidation in Air. Ann. Phys. 1934, 19, 465.

(69) Levin, I.; Brandon, D. Metastable Alumina Polymorphs: Crystal Structures and Transitions Sequences. J. Am. Ceram. Soc. 1998, 81(8), 1995-2012.

(70) Pei, H. B.; Jiao, Q. J.; Qin, J. F. Reaction Process of Aluminized RDX-based Explosives Based on Cylinder Test. Explos. Shock Waves 2013, 34(5), 636-640.

(71) Feng, X. J.; Huang, Y. F.; Xu, H. T. The Influence of Al on the Detonation Parameters of Aluminized Explosives. Initiators Pyrotech. 2012, 55(12), 3088-3093.

(72) Hu, R. Z.; Gao, S. L.; Zhao, F. Q.; Shi, Q. Z.; Zhang, T. L.; Zhang, J. J. Thermal Analysis Kinetics. 2nd ed.. Beijing: Science Press (in Chinese). 2008,

(73) Birch, F. Finite Elastic Strain of Cubic Crystals. Phys. Rev. 1947, 71(11), 809.

(74) Liu, Y.; Oganov, A. R.; Wang, S.; Zhu, Q.; Dong, X.; Kresse, G. Prediction of New Thermodynamically Stable Aluminum Oxides. Sci Rep. 2015, 5, 9518.

(75) Tsuchiya, J.; Tsuchiya, T.; Wentzcovitch, R. M. Transition from the $\mathrm{Rh}_{2} \mathrm{O}_{3}(\mathrm{II})$-to-CalrO $\mathrm{C}_{3}$ Structure and the High-pressure-temperature Phase Diagram of Alumina. Phys. Rev. B 2005, 72, 020103.

(76) Ono, S.; Oganov, A. R.; Koyama, T.; Shimizu, H. Stability and Compressibility of the High-pressure Phases of $\mathrm{Al}_{2} \mathrm{O}_{3}$ up to $200 \mathrm{GPa}$ : Implications for the Electrical Conductivity of the Base of the Lower Mantle. Earth Planet. Sci. Lett. 2006, 246, 326-335.

(77) Raymand, D.; van Duin, A. C. T.; Baudin, M.; Hermansson, K. A Reactive Force Field (ReaxFF) for Zinc Oxide. Surf. Sci. 2008, 602, 1020-1031.

(78) Brill, T. B.; Gongwer, P. E.; Williams, G. K. Thermal Decomposition of Energetic Materials. 66 Kinetic Compensation Effects in HMX, RDX, and NTO. J. Phys. Chem. 1994, 98, 12242-12247.

(79) Fathollahi, M.; Mohammadi, B.; Mohammadi, J. Kinetic Investigation on Thermal Decomposition of Hexahydro-1,3,5-trinitro-1,3,5-triazine (RDX) Nanoparticles. Fuel 2013, 104, 95-100.

(80) Liang, L.; Wang, J. Y.; Dong, J.; An, C. W. Effects of Nano-Al Powder on the Thermal Decomposition Catalytic Performance of Nitroamine Explosives. Chin. J. Explos. Propellants 2009, 32(6), 75-78.

(81) Liu, R.; Yang, L.; Zhou, Z. N.; Zhang, T. L. Thermal Stability and Sensitivity of RDX-based Aluminized Explosives. J. Therm. Anal. Calorim. 2014, 115, 1939-1948.

(82) Miao, X.; Xu, H. X.; Zhao, X. P.; Pei, Q.; Pang, W. Q.; Wang, G. Q. Safety of Nano-Al / RDX Mixtures. Chin. J. Explos. Propellants 2015, 38(5), 69-73.

(83) Yao, E. G.; Zhao, F. Q.; Gao, H. X.; Xu, S. Y.; Hu, R. Z. Thermal Behavior and Non-isothermal Decomposition Reaction Kinetics of Aluminum Nanopowders Coated with an Oleic Acid/Hexogen Composite System. Acta Phys. -Chim. Sin. 2012, 28(4), 781-786.

(84) Zheng, Y. F.; Nan, H.; Xi, P.; Li, K.; Chen, C. Y. Research of Thermal Decomposition Activation Energy on Al-RDX Hybrid Explosives with Different Components Ratio. Explos. Mater. 2015, 44(5), 14-17.

(85) Deal, B. E.; Grove, A. S. General Relationship for the Thermal Oxidation of Silicon. J. Appl. Phys. 1965, 36, 3770 .

TOC Graphic 
1

2

3

4

5

6

7

8

9

10

11

12

13

14

15

16

17

18

19

20

21

22

23

24

25

26

27

28

29

30

31

32

33

34

35

36

37

38

39

40

41

42

43

44

45

46

47

48

49

50

51

52

53

54

55

56

57

58

59

60

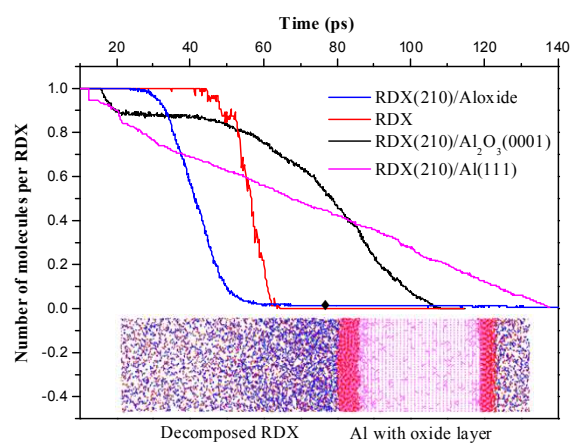

